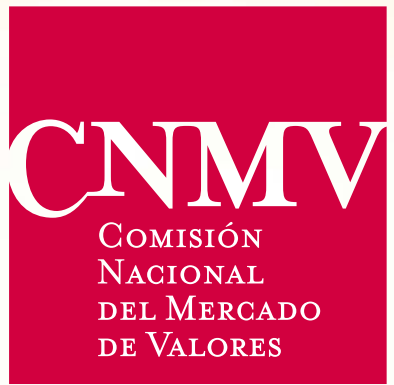

The Nature of Volatility

Spillovers across the International Capital Markets

Gustavo Peralta

Documentos de Trabajo $N^{\circ} 63$ 



\section{The Nature of Volatility Spillovers across the International Capital Markets}

Gustavo Peralta $\left({ }^{*}\right)$

Documentos de Trabajo

$N^{\circ} 63$

September 2016

$\left(^{*}\right.$ Gustavo Peralta (corresponding author) is with the Department of Research and Statistics at CNMV and with the Department of Business Administration at Universidad Carlos III de Madrid. Email: gperalta@cnmv.es 
Gustavo Peralta is a member of the Research, Statistics and Publications Department, CNMV.

The opinions in this Working Paper are the sole responsibility of the authors and they do not necessarily coincide with those of the CNMV.

The CNMV publishes this Working Paper Series to enhance research and contribute towards greater knowledge of the stock markets and their regulation.

The CNMV distributes its reports and publications via the internet at www.cnmv.es

(C) CNMV. The contents of this publication may be reproduced, subject to attribution.

Gustavo Peralta pertenece al Departamento de Estudios, Estadísticas y Publicaciones de la CNMV.

Las opiniones expresadas en este documento relejan exclusivamente el criterio de los autores y no deben ser atribuidas a la Comisión Nacional del Mercado de Valores.

La Comisión Nacional del Mercado de Valores, al publicar esta serie, pretende facilitar la difusión de estudios que contribuyan al mejor conocimiento de los mercados de valores y su regulación.

La Comisión Nacional del Mercado de Valores difunde la mayoría de sus publicaciones a través de la red Internet en la dirección www.cnmv.es

(C) CNMV. Se autoriza la reproducción de los contenidos de esta publicación siempre que se mencione su procedencia.

ISSN (edición electrónica): 2172-7147

Maqueta: Composiciones Rali, S.A. 


\section{Abstract}

This paper studies the nature of volatility spillovers across countries from the perspective of network theory and by relying on data of US-listed ETFs. I use a Lassorelated technique to estimate the International Volatility Network (IVN) where the nodes correspond to large-cap international stock markets while the links account for significant volatility lead-lags. Also included in the analysis is the International Trade Network (ITN), whose links measure bilateral export-import flows thus, capturing fundamental interconnections between countries. I find that the IVN and the ITN resemble each other closely pointing out that volatility does not disseminate randomly but tends to spread across fundamentally related economies. I also note that the lagged volatility reactions embedded in the IVN are consistent with the notion of gradual diffusion of information across investors who are subject to limited attention and home bias. This hypothesis is formally tested by using as a direct proxy of investors' attention the aggregate search frequency in Google. The empirical results support this intuition indicating that higher volatility surprises in key foreign markets predict higher domestic attention upon those markets in subsequent days. Once domestic attention is captured by such external shocks, it is contemporaneously transformed into higher domestic volatility.

Keywords: Network Theory, Spillover of Volatility, International Financial Contagion.

JEL Classification: Coo, $\mathrm{C}_{32}, \mathrm{C}_{45}, \mathrm{C}_{5}$ 1, C55, C58, F30, F36, Go1, G10, G15, G17. 



\section{General index}

The International Volatility Network

3.1 Network statistics

$\begin{array}{llr}4.1 & \text { ETF Market Data } & 23\end{array}$

\begin{tabular}{llr}
\hline 4.2 & Trade Data & 24
\end{tabular}

\begin{tabular}{lll}
\hline $4.3 \quad$ Google Search Index Data & 24
\end{tabular}

$5 \quad$ Empirical Framework $\quad 27$

$\begin{array}{llr}6 & \text { Empirical Results } & 29\end{array}$

\begin{tabular}{llr}
\hline $6.1 \quad$ Descriptive statistics & 29
\end{tabular}

6.2 Describing the International Volatility Network 31

6.2 Describing the International Volatility Network 31

$7 \quad$ The Major Drivers of Volatility Spillovers $\quad 35$

7.1 Why does volatility tend to spread strongly towards other countries from the same continent? 35

$\begin{array}{lll}7.2 & \text { Why does volatility spread with lags? } & 42\end{array}$

7.2 Why does volatility spread with lags?

$8 \quad$ Conclusions and Future Research Lines

Appendix A. Estimation of the IVN 



\section{Index of Figures}

\begin{tabular}{llr} 
FIGURE 1 & Prices and volatilities across major international markets & 12 \\
\hline FIGURE 2 & ETFs as part of the fund industry for the US market & 16 \\
\hline FIGURE 3 & The creation of ETF shares & 17 \\
\hline FIGURE 4 & Distributions of Annualized Volatility by Countries & 30 \\
\hline FIGURE 5 & The undirected International Volatility Network & 31 \\
\hline FIGURE 6 & The International Trade Network & 37 \\
\hline FIGURE 7 & Graphical representations of the adjacency matrices of the IVN and the ITN & 38 \\
\hline FIGURE 8 & Relationship between the weights of the links across the IVN and the ITN & 39 \\
\hline FIGURE 9 & Centrality of countries in the IVN and in the ITN & 41 \\
\hline FIGURE 10 & Delayed reaction of domestic attention to the Chinese Black Monday \\
\hline FIGURE 11 & Domestic attention as a channel from foreign shocks to domestic shocks & 43 \\
\hline
\end{tabular}

\section{Index of Tables}

\begin{tabular}{llr} 
TABLE 1 & Sample of international ETFs included in the analysis & 24 \\
\hline TABLE 2 & Descriptive statistics of the annualized volatilities for the period 2013-6 to 2015-12 & 29 \\
\hline TABLE 3 & Descriptive statistics of the volatility residuals for the period 2013-6 to 2015-12 & 30 \\
\hline TABLE 4 & Adjacency matrix of the Granger IVN & 32 \\
\hline TABLE 5 & Network degree by countries for the directed IVN & 33 \\
\hline
\end{tabular}


TABLE 7

TABLE 8

Non-random link ovelapping between the IVN and the ITN

TABLE 9

TABLE 10

The effects of domestic attention on domestic volatility 


\section{Introduction}

The occurrence of recent financial events with negative and widespread consequences has renewed interest in the timeless debate about international spillovers. To stimulate the discussion, figure 1 plots the closing prices (left panel) and the return volatility (right panel) for three US-listed ETFs tracking the German, US and Japanese MSCI market indices during the period Jun-2015 to Dec-2015. Note that the effects of the so-called Chinese Black Monday on August 24, 2015 were immediately evident worldwide with negative log returns of $-1.5 \%,-4.3 \%$ and $-3.6 \%$ for the German, US and Japanese ETFs, respectively. The case of market volatility is particularly striking since return variances achieved levels more than 20 times larger than average (over the analyzed period) for the German and Japanese securities and more than 40 times larger for the case of the US.

An appropriate assessment of the risks stemming from financial contagion and a sound international diversification crucially depends on our understanding of the shock-transmission mechanisms across economies. Academic papers have devoted substantial efforts to identifying the fundamental drivers behind returns' spillovers among major financial centers (e.g. King and Wadhwani (1990), Hamao, Masulis, and Ng (1990), Lin, Engle, and Ito (1994)). Despite the fundamental importance of the issue, studies specifically concerned with the transmission of volatility among a large panel of countries have not received as much attention until recently (Jung and Maderitsch (2014), Diebold and Yilmaz (2014), Diebold and Yilmaz (2009), Diebold and Yilmaz (2012)). The current study contributes to this latter strand of the literature by uncovering the detailed patterns of volatility spillovers among a panel of countries that jointly represent more than $80 \%$ of the worldwide market capitalization. Careful analysis has gone into identifying volatility spillovers; however, the final goal of the paper is to shed some light on the mechanisms leading such interactions. I undertake this task by estimating the International Volatility Network (IVN), in which the nodes correspond to a set of large-cap international stock markets while the links account for significant volatility lead-lags. ${ }^{1}$

As discussed by Strohsal and Weber (2012), the concept of market volatility has been ambiguously used in the financial literature as a proxy of the flow of fundamental information arriving at the market and as a measure of investor's uncertainty. Consequently, volatility spillovers across countries can be associated with the transmission of valuable information across fundamentally interrelated economies or with the transfer of pure uncertainty. I explore these intuitions by comparing the IVN with another network built upon data on international trades. This In- 

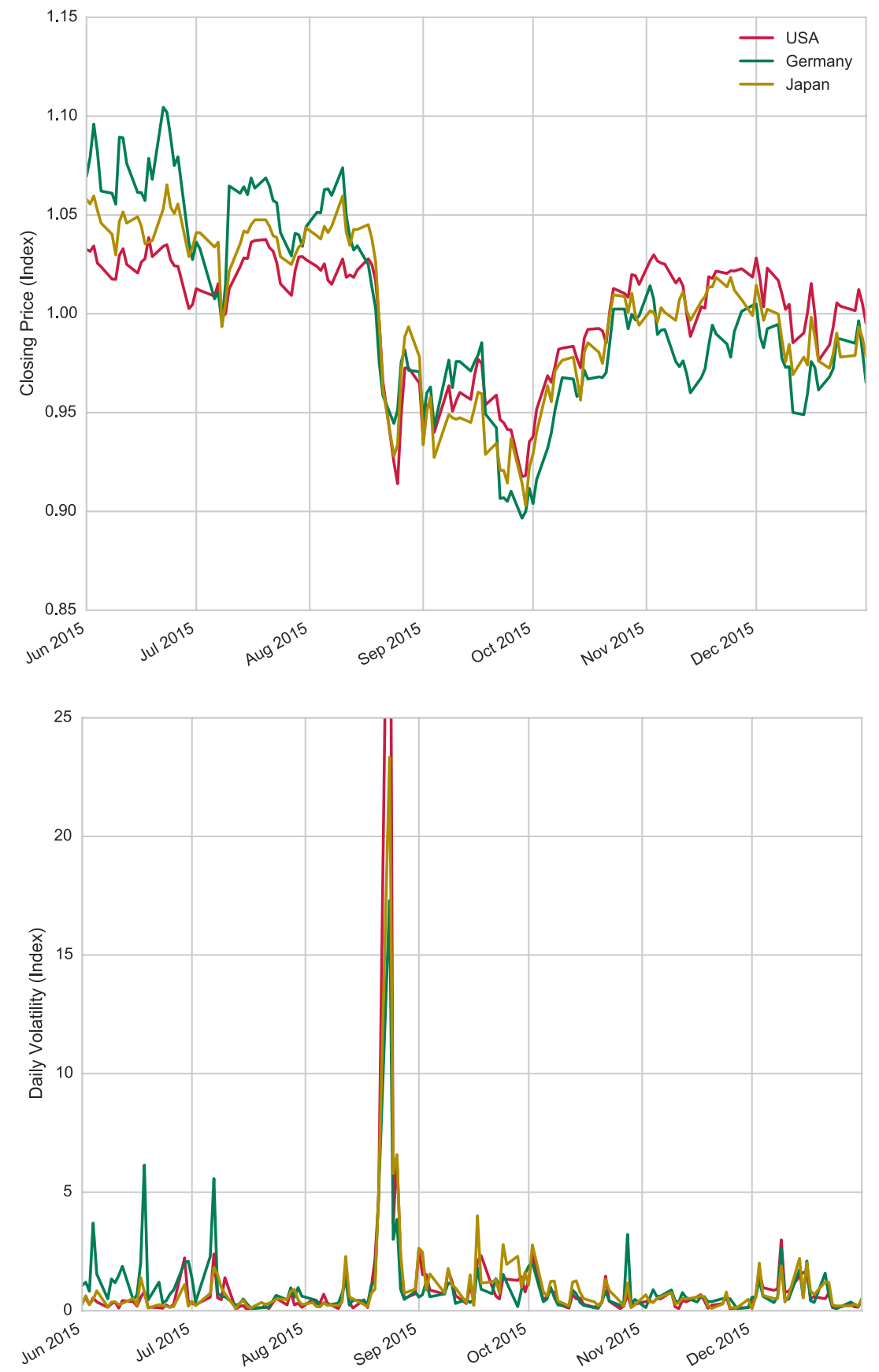

Daily closing prices and range-based volatilities (see equation 3 ) for the iShare ETFs tracking the MSCI indices of the US, German and Japanese market. The series are scaled by their mean value during the period Aug2015 to Dec-2015.

ternational Trade Network (ITN) is formed by the same set of nodes as in the IVNs while the weights of the links account for the value of bilateral export-import flows. In the case that international trades are sufficient statistics for the "fundamental" interconnections between pairs of economies and market volatilities carry economically relevant information, then the IVN and the ITN should resemble each other closely. Otherwise, the ITN would be a sort of sub-structure embedded into the IVN, whose excess interconnections would represent the channel through which uncertainty-related shocks flow. 
To estimate the IVNs, I implement Adaptive Lasso (Zou, 2006) upon daily data of US-listed ETFs. This sample covers the period Jun-2013 to Dec-2015 and includes 17 international ETFs most of which belong to the MSCI iShare family. The main benefit of using ETFs instead of market indices is that it allows the use of a large panel of countries without the need for cumbersome data adjustments due to non-overlapping trading hours. Therefore, I can exploit the informational efficiency property of ETFs that has been previously investigated in the literature (Khorana, Nelling, and Tester (1998), Tse and Martinez (2007)). To identify the ITN, I gather data from the DOT database maintained by the International Monetary Fund regarding the value of bilateral exports and imports for the same period and countries as in the ETF dataset.

From the analysis of the estimated IVN two features of the data emerge that deserve further attention and analysis. Firstly, the lead-lags of volatilities are more frequent and stronger among countries from the same continent than between countries in different continents unveiling a network organized in communities. Secondly, it is hard to reconcile the cross-predictability observed in the panel of volatilities with the efficient market hypothesis. In order to explain the first of these features, I compare the IVN with the ITN from different perspectives finding that: $i$ ) the slope coefficient that results by regressing the weights of the links from the IVN on the weights of the same links from the ITN is positive and statistically significant, ii) the amount of overlapping links between the IVN and ITN is unlikely to be generated by random arrangements of connections and iii) the correlation between the rankings of centrality of countries across these structures is positive. All of these results indicate the informational content of market volatility and its tendency to spread across economically related countries. Furthermore, the data also shows that Asian markets, say Hong Kong, China, Singapore and Japan, are systematically more central as volatility spreaders than as trade partners, which might explain the international reaction upon the Chinese Black Monday.

Regarding the second feature of the $I V N$, the nature of volatility lead-lags might be explained by the gradual diffusion of information hypothesis, whereby information slowly spreads as a consequence of the limited attention paid by domestic investors to foreign markets (Hong and Stein, 2007; Hou, 2007; Cohen and Frazzini, 2008; Menzly and Ozbas, 2010). I empirically investigated this intuition using as a direct proxy of attention the aggregate frequency of internet searches in Google as proposed by Da, Engelberg, and Gao (2011). In particular, I obtain data from Google Trend (https://www.google.com/trends/) to create variables that account for the internet search volume arising in a given domestic country concerning the stock market index of another foreign country. These variables are used as measures of domestic investors' attention to foreign markets. I theorize that specialized investors subject to home bias (French and Poterba, 1991, Faruqee, Li, and Yan, 2004, Van Nieuwerburgh and Veldkamp, 2009) rapidly incorporate innovation arising in domestic markets while processing the news from other fundamentally interrelated economies with some delay. The empirical results on this support these arguments: the evidence indicates that domestic attention to the markets of major trade partners reacts to volatility surprises arising in those markets with some delay. The data also shows that once foreign news captures the attention of domestic investors, it is contemporaneously incorporated into the prices of domestic securities. 
This study is built upon the growing literature of networks based on financial time series (Billio et al. (2012), Diebold and Yilmaz (2014), Hautsch, Schaumburg, and Schienle (2015), Tse, Liu, and Lau (2010), Peralta (2015), Barigozzi and Brownlees (2016)). The closest papers to this manuscript are Diebold and Yilmaz (2014), Diebold and Yilmaz (2015), however, the former is particular concerned only with US securities while the latter considers American and European stocks restricted only to the financial sector. To my knowledge, this is the first study combining ETF data with network theory in order to shed light on the nature of volatility spillovers across countries.

The remainder of this paper is organized as follows. Section 2 discusses salient features of the ETF market highlighting the informational efficiency of this asset class. Section 3 introduces the International Volatility Network and provides fundamental definitions of network measures. Section 4 describes the datasets used in this study while section 5 specifies the empirical framework. Section 6 reports the main empirical results regarding the estimation of the IVN. Section 7 formally tests the major drivers explaining the observed volatility lead-lags contained in the IVN. Finally, section 8 concludes and outlines future research lines. 


\section{The Informational Efficiency of ETFs}

The subsequent empirical analysis strongly relies on ETF data to analyze volatility spillovers across countries instead of the commonly used broad market indices. This is a way to avoid the required data adjustments due to non-overlapping trading hours across markets and it is justified by the informational efficiency of this assets class as discussed below.

In a nutshell, Exchange-Traded Funds (ETFs) are pooled investment vehicles designed to passively track the performance of a benchmark index, thus giving investors the benefits of the financial diversification offered by a broad index in just one trade. The first ETF was launched in 1993 with the goal of replicating the S\&P-500 index and since then, this class of financial assets has shown striking growth. In accordance with the Investment Company Institute (2015), the assets under management of ETFs stood at nearly \$2 trillion at year-end 2014 for the US market, representing $11 \%$ of the total Net Asset Value (NAV) managed by this industry (see figure 2). The acceptance of this type of securities has been remarkable, as evidenced by its mean annual growth rate during 2004-2014 of $24.1 \%$, more than three times larger than similar measure for the same period for the traditional mutual fund industry $(7.0 \%)$. Among the different segments of the ETF industry, those securities targeting country-specific indices represent the second largest category accounting for almost $21 \%$ of the industry's NAV (Investment Company Institute, 2015).

As stated in Gastineau (2010), there are many differences between the shares of ETFs and the shares of Equity Index Mutual Funds (MF). Among them it is worth mentioning that: (i) ETFs' shares are continuously traded during a trading day at a market-determined price like any other common stock. In contrast, MFs' shares are not listed securities and have to be bought and sold at end-of-day NAV, (ii) ETFs can be purchased on margin or sold short, which the equivalent MFs cannot, (iii) despite tracking errors in both asset classes, the intra-day divergence between the NAVs and market prices for ETFs is constrained and short-lived in practice thanks to the internal mechanism of in-kind creation and redemption of shares (see below). Since there are no market prices for an open-end MF this comparison is meaningless while for closed-end MFs the difference can be substantial.

The informational efficiency of ETFs is ensured through the in-kind creation and redemption of shares that prevents large differences between market prices and NAVs. ETFs' shares are created when an Authorized Participant (AP), usually a large financial firm, deposits the creation basket into the fund in exchange for the ETFs' shares. These newly created shares are subsequently traded in the market like any other ordinary stock (see figure 3). ETF shares are redeemed when the AP returns some of its shares to the fund in exchange for the redemption basket. The creation and redemption of ETF shares are referred to as primary market operations while the subsequent trades of outstanding shares are secondary market operations. 

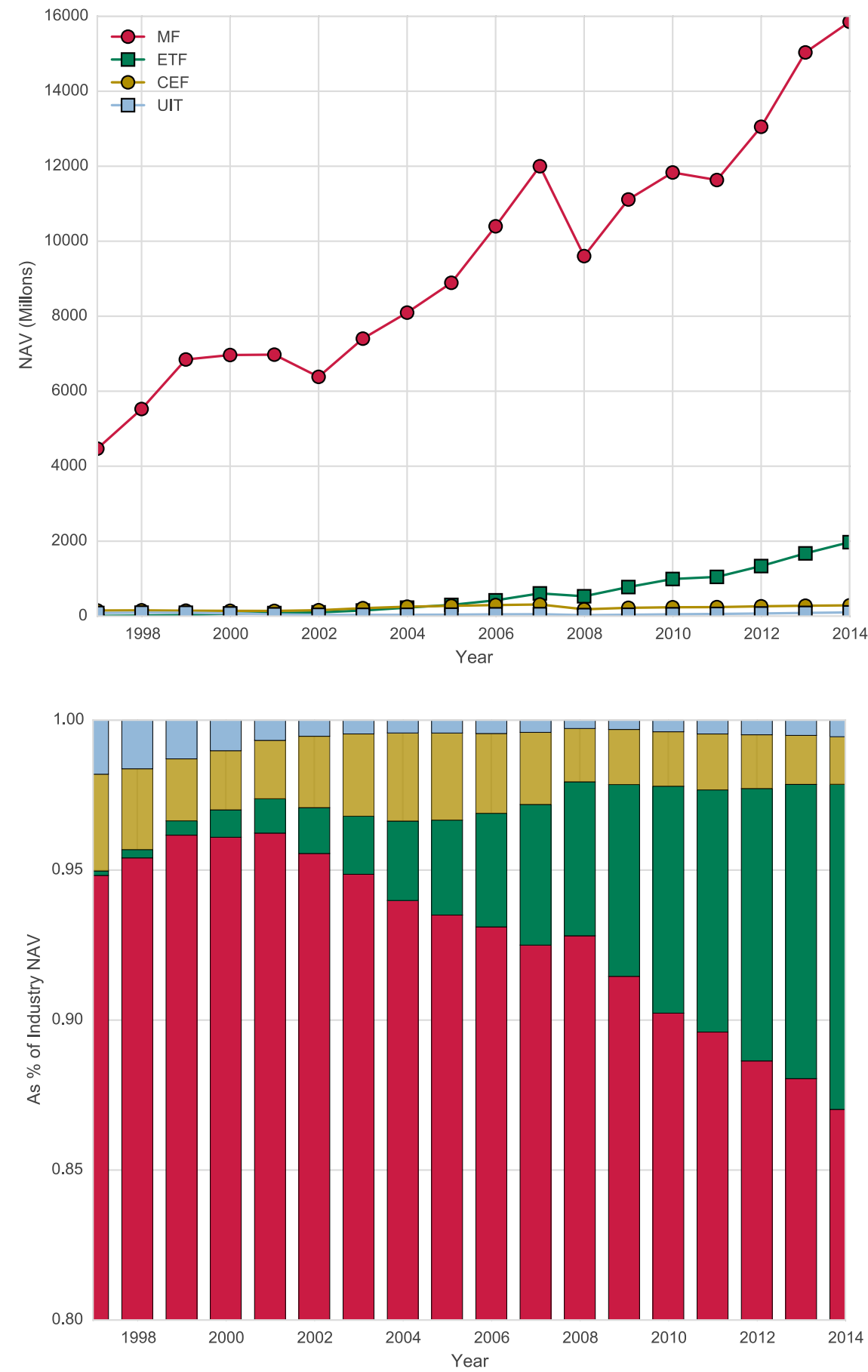

Total Net Asset Value by categories of investment firms in Millions of US dollars (left panel) and as a percentage of the total (right panel). The references are as follows: Open-end Mutual Fund (MF), Exchange-Traded Funds (ETF), Closed-end Mutual Fund (CEF) and Unit Investment Trust (UIT).

Source: Investment Company Institute (2015). 


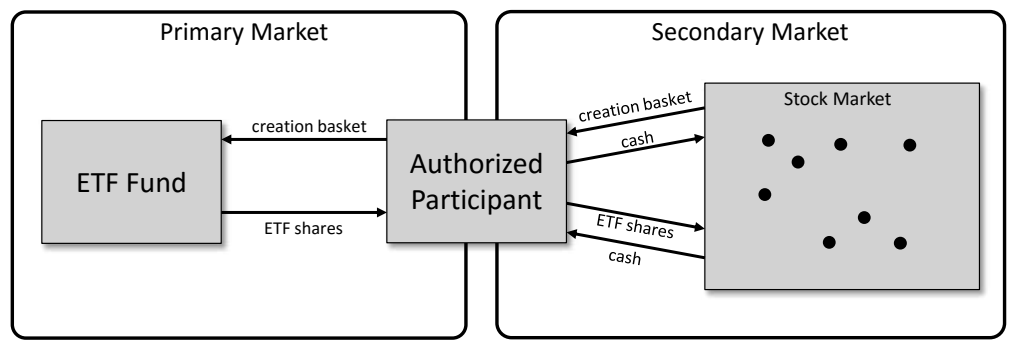

The redemption process follows the same steps but reversing the direction of the arrows.

What is important to note is that any divergence between NAVs and market prices must be short-lived; otherwise, free-lunch profit can be traded by the AP through the mechanism of creation and redemption of shares. If the price of an ETF's shares is below NAV, the AP can buy these shares in the market and redeem them with the fund in exchange for the redemption basket, thus gaining the difference between them. On the other hand, if the market price of the ETF is above NAV, the AP could buy the creation basket and deposit it to the fund in exchange for new ETF shares. Again, this provides the AP with the profit from the difference. ${ }^{2}$ The notion of ETFs as highly efficient assets is not just a theoretical argument since it is also supported by substantial empirical evidence. Khorana, Nelling, and Tester (1998) and Tse and Martinez (2007) highlight the good performance of international ETFs in tracking the corresponding indices. In the same line of argument, Hughen and Mathew (2009) points out the relative efficiency of ETFs versus closed-end MFs showing that they are more accurate and faster when incorporating changes in foreign NAVs into their prices.

2 In addition, since ETFs are obliged to disclose the creation and redemption baskets of securities on a daily basis, the gap between NAVs and market prices is further discouraged. 



\section{The International Volatility Network}

In general terms, a network $\Phi=\{N, \omega\}$ is composed by the set of nodes $N=\{1,2, \ldots, n\}$ and the set of links $\omega$ connecting pairs of them. If there is a link from node $i$ to $j$, it is indicated as $(i, j) \in \omega$. A convenient rearrangement of the information contained in $\omega$ is provided by the $n \times n$ adjacency matrix $H=\left[h_{i j}\right]$ whose element $h_{i j} \neq 0$ whenever $(i, j) \in \omega$. Accordingly, the sets $\{N, \omega\}$ and $\{N, H\}$ are two different ways to represent the same structure. The network $\Phi$ is said to be undirected if no-causal relationships are attached to the links which, in turns, implies that $H=H^{\prime}$ since $(i, j) \in \omega \Leftrightarrow(j, i) \in \omega$. When $h_{i j}$ entails a causal association from node $j$ to node $i$, $\Phi$ is said to be directed. In this case, it is likely that $H \neq H^{\prime}$ since $(i, j) \in \omega$ does not necessarily imply $(j, i) \in \omega$. For unweighted networks, $h_{i j} \in\{0,1\}$ and therefore only on/ off relationships exist. On the contrary, when $h_{i j} \in \mathbb{R}$, the links track the intensity of the interactions between nodes giving rise to weighted networks. ${ }^{3}$

The International Volatility Network $(I V N)$ is a structure capturing the cross sectional and serial dependency among the time series of market volatilities from a sample of countries. Let us consider that the $n$-dimensional vector of returns volatilities is indicated by $\sigma_{t}=\left[\sigma_{i, t}\right]$ where each element $\sigma_{i, t}$ accounts for the volatility of the capital market of country $i$ at period $t$. Let us assume that $\sigma_{t}$ follows an $n$-dimensional and stationary Vector Autoregressive model of order 1, $\operatorname{VAR}(1)$, as stated in equation $(1)^{4}$. As discussed by Andersen et al. (2003), modeling $\sigma_{t}$ through a VAR process provides some benefits in comparison with more complicated $A R C H$ specifications and this is the approach considered in this study.

$$
\sigma_{t}=B \quad \sigma_{t-1}+u_{t}, \quad u_{t} \sim \text { w.n. }(\mathrm{O}, \Theta)
$$

The elements $b_{i j}$ from the $n \times n$ coefficient matrix $B$ represent the impact of country's $j$ volatility in period $t-1$ on country's $i$ volatility in period $t$ while $\Theta$ is the covariance matrix of residuals. In a similar fashion to Barigozzi and Brownlees (2016), let us formally introduce the Granger IVN (or just $I V N$ for short) as follows:

Definition 1: The International Volatility Network (IVN) is a weighted and directed network denoted by $\Phi^{D}=\left(N, B=\left[b_{i j}\right]\right)$ where $N$ is the set of country-specific capital markets and $B$ from equation (1) is the corresponding adjacency matrix.

Since the links of network $\Phi^{D}$ account for volatility lead-lag relationships among the sample countries, it allows to analyze of the transmission mechanism across econo-

3 The reader is referred to Jackson (2010) or Newman (2010) for a comprehensive treatment of the network literature.

4 It is assumed that the vector $\sigma_{t}$ is centered thus discarding the constant term in (1). 
mies. By discarding the directionality of the links in $\Phi^{D}$, the undirected version of the IVN is defined as follows

Definition 2: The undirected International Volatility Network is a weighted and undirected network denoted by $\Phi^{U}=\left(N, \tilde{B}=\left[\tilde{b}_{i j}\right]\right)$ where $N$ is the set of countryspecific capital markets and $\tilde{B}=\frac{1}{2}\left(B+B^{\prime}\right)$ where $B$ is the adjacency matrix of $\Phi^{D}$.

Note that the network $\Phi^{U}$ disregards the direction of the flow of the volatility since there is a connection in the structure between countries $i$ and $j$ as long as either $b_{i j}$ or $b_{j i}$ is not zero.

\subsection{Network statistics}

Given that several network statistics are reported across the study, I collect and define them in this subsection to enhance readability. Node-size and link-size account for the number of nodes and links in the network $\Phi=\left(N, H=\left[h_{i j}\right]\right)$. The density of $\Phi$ measures the fraction of links that actually exist relative to the maximum possible number of links in the structure.

For undirected networks, the degree of node $i$ is the number of links attached to it while the mean degree of $\Phi$ captures the average number of links per node. The degree distribution of $\Phi$ represents the empirical distribution of nodes' degrees. For directed networks, the in-degree of node $i$ is the number of incoming links attached to it while the out-degree of node $i$ accounts for the number of its outgoing links. Directed networks also have an in-degree distribution and an out-degree distribution with similar interpretation to the degree distribution for undirected structures. Since an outgoing-link from node $i$ corresponds to an incoming-link to node $j$, the mean in-degree of $\Phi$ must be equal to its mean out-degree.

An important part of the network literature is devoted to quantifying the importance/ influence of nodes in a given structure. The most basic centrality measure is degree centrality simply accounting for the degrees of the nodes. Therefore, node $i$ is relatively more central than $j$ as long as the degree of node $i$ is larger than the degree of node $j$. An extension to degree centrality is provided by the eigenvector centrality studied in Bonacich (1972), Bonacich (1987), Bonacich (2007) and generalized to weighted networks by Newman (2004). The eigenvector centrality of node $i$, denoted by $v_{i}$, corresponds to the weighted sum of its neighbors' eigenvector centrality where the elements of the corresponding adjacency matrix $h_{i j}$ are the weighting factors as in equation (2). Therefore, node $i$ is central as long as it is connected to many other central nodes.

$$
v_{i}=\lambda^{-1} \sum_{j} h_{i j} v_{j}
$$

By restating expression (2) in matrix terms, we obtain $\lambda v=H v$ indicating that the centrality vector $v$ is proportional to the eigenvector of the adjacency matrix $H$ corresponding to largest eigenvalue $\lambda .{ }^{5}$

5 In principle each eigenvectors of $H$ is a solution to equation to (2). However, the centrality vector corresponding to the largest component in the network is given by the eigenvector corresponding to the largest eigenvalue (Bonacich, 1972). 
Finally, the assortativity coefficient $r$ (Newman (2003)) quantifies the extent to which a particular network is organized in communities where "communities" refers to groups of nodes tightly interconnected within each group but weakly interconnected across groups. Let us assume that the nodes of $\Phi$ can be grouped into a set of exclusive and exhaustive categories. Then, $r$ measures how likely we are to observe the amount of links connecting nodes from the same category relative to what would be expected from a random arrangement. The coefficient $r$ is found in $[\underline{r}, 1]$ where $1, O$ and $\underline{r}$ correspond to perfect positive assortativity (nodes belonging to a particular category are only connected to other nodes from the same category), pure random mixing and perfect disassortativity (nodes belonging to a particular category are only connected to nodes from a different category). 



\section{Data}

The subsequent empirical analysis relies on the combination of three different datasets: i) price data on a set of US-listed ETFs tracking the stock markets of a sample of economies, ii) data on the bilateral export and import flows among those economies and iii) a measure of investors' attention to specific markets as captured by the search frequency of the corresponding stock market indices in Google.

\subsection{ETF Market Data}

In order to quantify volatility spillovers among economies while avoiding the required adjustments due to non-overlapping trading hours across markets, I exploit the informational efficiency shown by ETFs as discussed in section 2 (see Appendix B for a detail description of opening and closing times for the countries in the sample). I collect daily data on Open, Close, High and Low prices for a panel of US-listed ETFs tracking the Morgan Stanley Capital International (MSCI) indices corresponding to major financial centers. ${ }^{6}$ This data is gathered from Datastream and covers the period Jun-2013 to Dec-2015. The selected securities belong to the iShare ETF family except for the security replicating the US market, where SPDR, which has the S\&P-500 as its target index, is considered. The final sample comprises 17 countries where 16 are categorized as developed economies by MCSI Inc. plus China as an additional emerging market. It is worth mentioning that the final sample of countries results by discarding iShare ETFs from the set of developed economies when missing data is detected or when the daily average turnover during Dec-2015 is below 100.000 shares. $^{7}$

Table 1 reports the list of countries included in the sample, their total market capitalization as reported by the Bloomberg and some other variables characterizing the corresponding ETFs. Note that the set of selected economies represents more than $80 \%$ of worldwide market capitalization, thus providing a global perspective.

$6 \mathrm{MSCl}$ indices are cap-weighted indices commonly used for tracking the performances of particular international capital markets or sectors where broad coverage and comparability are a major concern.

7 Except for Austria with average daily turnover of 97.000 which is very close to the predefined threshold. 


\begin{tabular}{|c|c|c|c|c|c|c|c|}
\hline \multirow[b]{2}{*}{ Countries } & \multirow[b]{2}{*}{$\begin{array}{l}\text { Short } \\
\text { Name }\end{array}$} & \multicolumn{2}{|c|}{ Market Capitalization (a) } & \multirow[b]{2}{*}{ Benchmark Index } & \multirow[b]{2}{*}{ Ticker } & \multirow[b]{2}{*}{$\begin{array}{c}\text { Total NAV } \\
\text { (Millons \$) (b) }\end{array}$} & \multirow{2}{*}{$\begin{array}{c}\text { Avr Daily } \\
\text { Turover } \\
\text { (Thousands) (c) }\end{array}$} \\
\hline & & Bill \$ & $\%$ & & & & \\
\hline \multicolumn{8}{|l|}{ North America } \\
\hline Canada & CAN & 1,576 & $2.7 \%$ & MSCI Canada & EWC & $1,639.70$ & 3,286 \\
\hline United States & USA & 21,520 & $37.0 \%$ & S\&P 500 & SPY & $169,154.66$ & 195,418 \\
\hline \multicolumn{8}{|l|}{ Europe } \\
\hline Austria & AUT & 88 & $0.2 \%$ & MSCI Austria IMI 25/50 & EWO & 50.63 & 97 \\
\hline Belgium & BEL & 376 & $0.6 \%$ & MSCI Belgium IMI 25/50 & EWK & 203.94 & 321 \\
\hline France & FRA & 1,759 & $3.0 \%$ & MSCI France & EWQ & 358.88 & 2,058 \\
\hline Germany & DEU & 1,626 & $2.8 \%$ & MSCI Germany & EWG & $5,517.67$ & 8,521 \\
\hline Italy & ITA & 494 & $0.8 \%$ & MSCI Italy $25 / 50$ & EWI & 809.99 & 3,200 \\
\hline Netherlands & NLD & 371 & $0.6 \%$ & MSCI Netherlands Investable & EWN & 143.05 & 353 \\
\hline Spain & ESP & 568 & $1.0 \%$ & MSCI Spain 25/50 & EWP & 958.61 & 2,435 \\
\hline Sweden & SWE & 619 & $1.1 \%$ & MSCI Sweden & EWD & 296.36 & 453 \\
\hline Switzerland & $\mathrm{CHE}$ & 1,377 & $2.4 \%$ & MSCI Switzerland 25/50 & EWL & $1,144.60$ & 1,763 \\
\hline United Kingdom & GBR & 2,996 & $5.1 \%$ & MSCI United Kingdom & EWU & $2,177.16$ & 5,819 \\
\hline \multicolumn{8}{|l|}{ Asia-Pacific } \\
\hline Australia & AUS & 964 & $1.7 \%$ & MSCI Australia & EWA & $1,159.50$ & 4,374 \\
\hline China & $\mathrm{CHN}$ & 5,772 & $9.9 \%$ & MSCI China Index & $\mathrm{MCHI}$ & $1,750.65$ & 1,438 \\
\hline Hong Kong & $\mathrm{HK}$ & 3,573 & $6.1 \%$ & MSCI Hong Kong & EWH & $1,913.06$ & 6,894 \\
\hline Japan & JPN & 4,511 & $7.7 \%$ & MSCI Japan & EWJ & $18,942.19$ & 66,016 \\
\hline Singapore & SGP & 442 & $0.8 \%$ & MSCI Singapore & EWS & 460.88 & 2,196 \\
\hline
\end{tabular}

(a) Retrieved from Bloomberg for Feb 24, 2016 and \% corresponds to the proportion relative to the worlwide market capitalization

(b) Retrieved from in www.ishares.com for Dec 31, 2015 and from www.spdrs.com for Feb 08, 2016.

(c) Retrieved from Datastream. Average Turnover are in thousands and correspond to December of 2015.

\subsection{Trade Data}

For each of the countries included in the sample, I obtain monthly records of their bilateral total export and import flows from the Direction of Trade Statistics (DOTS) database of the International Monetary Fund (IMF) on U.S. dollar value. ${ }^{8}$ This dataset allows the computation of trade links between pairs of countries which, in turn, will be used as proxies of fundamental interaction between economies. For consistency with the ETF dataset, I consider the cumulative monthly values of exports and imports for the period 2013-2015. Following Rizova (2010), the trade data starts 6 months in advance of the ETF data to ensure that the trade-links are publicly available at the time where investors react.

\subsection{Google Search Index Data}

Google, as the current leader in the internet search engine industry, ${ }^{9}$ makes available a detailed database regarding the aggregate volume of searches by internet users

8 Available in https://www.imf.org/en/data

9 With 64\% market share in Feb-16 according to comScore Inc. 
on specific search terms through its application Google Trends. ${ }^{10}$ As stated by Da, Engelberg, and Gao (2011), aggregate search frequency of specific items in Google (such as stock tickers) can be used as a direct and unambiguous measure of investors' attention, particularly for the retail segment. This data is publicly available from Jan-04 and can be filtered by the specific countries where the searches originated. Regarding frequency issues, Google Trends provides weekly data for time series of 3 to 36 months while provides daily data for time series shorter than 3 months. The raw information from Google Trends is standardized, therefore the actual number of searches for a given term is not available. This standardization assigns value 100 to the maximum of time series in a given data request and the rest of the data points are scaled accordingly.

I collect data from Google Trend using a web crawling program that inputs into the application the country that originates the search, the specific search term corresponding to the market index of a given country and the specific period of the data request. In order to be consistent with the ETF dataset, the internet search data are properly adjusted to match the time zone where the US market is open (GMT-5). To discard ambiguity about the different ways in which a given index is input into Google Trends, I only consider as search items the names of different market indices when they are recognized as such by the application. For instance, if IBEX 35 is recognized and suggested by Google Trend as the stock market index of Spain, then this item is maintained in the list of search terms, otherwise it is discarded. The complete list of search terms that are properly recognized as market index by Google Trend is composed of the following 12 items: S\&P/ASX200 (Australia), S\&P/TSX Composite Index (Canada), SSE Composite Index (China), CAC4O (France), DAX Performance Index (Germany), Hang Seng Index (Hong Kong), FTSE MIB (Italy), Nikkei 225 (Japan), AEX Index (Netherlands), IBEX 35 (Spain), FTSE 100 Index (United Kingdom) and S\&P 500 Index (United State). Unfortunately, this procedure discards the market indices of five countries from the list of search items that are included in the ETF dataset: Austria, Belgium, Singapore, Sweden and Switzerland.

The final goal is to build the daily Google Search Index denoted by $G S I_{t, i \rightarrow j}$ as a proxy of the attention paid by investors from country $i$ to the stock market of country $j$ in period $t$. In order to build $G S I_{t, i \rightarrow j}$ I merge the weekly time series of the search volume from country $i$ on the market index of country $j$ with the corresponding daily series. As previously explained, this merge is required since daily time series for periods larger than three months are not directly available. The merging process is as follows. For the weekly dataset, I assume that the index provided by Google Trends in a given week corresponds to the average search intensity during that week. I split this weekly information into days by calculating the search intensity ratio from the daily dataset. This variable is computed as the ratio between the search frequency for a given day over the average daily frequency during the corresponding week. Then, I multiply the weekly Google Trend index by the intensity ratios corresponding to the days of that week to obtain a daily split of the weekly index. I do this for each week in the sample. Finally, I re-standardize the resulting $G S I_{t, i \rightarrow j}$ series by assigning a value of 100 to their maximum and rescaling the rest of their data-points proportionally. Moreover, weekends are removed from this dataset 
since the market is close during these days. For technical reasons not reported by Google, some daily datasets erroneously present zero records for the first and last days of the request. To address this issue, I consider a one-month overlapping period for the daily data requests and then take the average of these indices as the corresponding $G S I_{t, i \rightarrow i^{*}}$

I loop for each country in the sample assuming the role of searching region (except for China in which Google's search engine is banned) and across each of the search items recognized by Google Trend as market indices as previously discussed. Since the period of this dataset is $2013-2015$, I end up merging 18 overlapping daily files of 3-month length with the corresponding weekly files of 36-month length for each of the $144(12 \times 12)$ combinations of searching region/searched index. 


\section{Empirical Framework}

As far as the volatility process is concerned, I assume that $\sigma_{t}$ follows a VAR model as indicated in equation (1). This volatility modeling is not new in the financial literature since similar approaches have been previously considered (see Diebold and Yilmaz (2014), Diebold and Yilmaz (2012), Diebold and Yilmaz (2009), Diebold and Yilmaz (2015), Barigozzi and Brownlees (2016), Jung and Maderitsch (2014), Andersen et al. (2003)). Additionally, I measure the volatility of country $i$ in period $t, \sigma_{i t}$, by applying a range-based volatility estimator to the data on the corresponding ETF, following Garman and Klass (1980). The selection of this estimator is based on its relative efficiency and robustness to microstructure noise (bid-ask bounce) as discussed by Alizadeh, Brandt, and Diebold (2002).

Let us assume that $p_{t, i}^{H} p_{t, i}^{L} p_{t, i}^{O}$ and $p_{t, i}^{C}$ account for the logarithm of the high, low, opening and closing price of country's $i$ ETF in period $t$, respectively. By introducing the next three auxiliary variables $u=\left(p_{t, i}^{H}-p_{t, i}^{O}\right), d=\left(p_{t, i}^{L}-p_{t, i}^{O}\right), c=\left(p_{t, i}^{C}-p_{t, i}^{O}\right)$ to simplify notation, a relatively efficient volatility estimators of $\sigma_{i t}$ is stated in equation (3) (see Garman and Klass 1980, p. 74)

$$
\hat{\sigma}_{t, i}^{2}=0.511(u-d)^{2}-0.019[c(u+d)-2 u d]-0.383 c^{2}
$$

There is convincing evidence supporting the existence of a systematic factor leading the auto- and cross-correlations of volatilities across countries (Alizadeh, Brandt, and Diebold (2002), Bekaert, Hodrick, and Zhang (2012), Dimpfl and Jung (2012)). Since this observation is inconsistent with the identification of sparse IVNs, I control for systematic components by applying the network estimation approach (which is described below) to the series of residuals $\varepsilon_{t, i}$ coming from the regressions stated in (4). Note that by construction, the elements $\varepsilon_{t, i}$ can be interpreted as volatility shocks of country $i$ in period $t$.

$$
\log \left(\hat{\sigma}_{t, i}^{2}\right)=\beta_{\circ}+\beta_{d} \gamma_{t, i}+\beta_{w} \gamma_{t, i}^{w}+\beta_{m} \gamma_{t, i}^{m}+\varepsilon_{t, i} \text { for } i=1,2, \ldots, n
$$

The variable $\gamma_{t, i}$ in (4) is the contemporaneous value of the first principal component of the panel of log volatility series while $\gamma_{t, i}^{w}$ and $\gamma_{t, i}^{m}$ correspond to its mean value over the weekly and monthly time horizon, respectively. There are two points arising from expression (4) that deserve some attention. First, since volatility distributions tend to be positively skewed, Andersen et al. (2003) suggests taking logarithms to obtain approximate normality which explains the left-hand side term in equation (4). Second, given that the estimated log volatilities present strong persistence with large autocorrelation coefficients even for 20 lags (see table 2 for descriptive statistics), I follow the approach of Jung and Maderitsch (2014) by including $\gamma_{t, i}^{w}$ and $\gamma_{t, i}^{m}$ instead of several lags of $\gamma_{t, i}$ with the aim to control for common factors with the most descriptive yet parsimonious model. 
The strategy to estimate the $I V N$ is as follows. I estimate the matrix $B$ from model (1) by implementing the Adaptive Lasso proposed by Zou (2006). The Least Absolute Shrinkage and Selection Operator method (Lasso) proposed by Tibshirani (1996) is specifically designed to improve OLS results by performing continued shrinkage on regression coefficients and automatic variable selection. Zou (2006) shows that $l_{1}$ regularized models must satisfy non trivial conditions to be an oracle procedure (consistency in selection and asymptotic normality). This leads the author to propose the Adaptive Lasso regressions to overcome such deficiency. I implement this technique by estimating equation (1) on a row-by-row basis by solving the following expression

$$
\hat{\beta}_{i}=\arg \min _{\beta_{i} \in \mathbb{R}_{+}^{n}}\left(\sum_{t=1}^{T}\left(\hat{\varepsilon}_{t, i}-\beta_{i} \hat{\varepsilon}_{t-1}\right)^{2}+\mu \sum_{j=1}^{n} \eta_{i j}\left|\beta_{i, j}\right|\right) \text { for } i=1,2, \ldots, n
$$

The elements of the weighting vector $\eta_{i}=\left(\eta_{i 1} \ldots \eta_{i n}\right)^{\prime}$ in (5) are computed as $\eta_{i j}=\left(\left|\tilde{\beta}_{i j}\right|\right)^{-v}$ where $\tilde{\beta}_{i j}$ denotes initial OLS coefficients that result from a regression of $\hat{\varepsilon}_{t, i}$ on $\hat{\varepsilon}_{t-1}$ and $|a|$ is the absolute value of $a$. Following the convention in the literature, explanatory variables are standardized before computing $\hat{\beta}_{i}$ while $(\mu, v)$ is selected by 3 -fold cross validation. See Appendix A for detailed description of the estimation methodology. 


\section{Empirical Results}

\subsection{Descriptive statistics}

The descriptive statistics for the annualized volatility series of the sampled ETFs are reported in table 2 where the first principal component of this panel is included for comparison. Most of the characteristics exhibited in this table, like positive skewness, excess kurtosis, large autocorrelations and strong persistence, have been previously reported in the literature (see Andersen et al. (2003), Jung and Maderitsch (2014)). Table 3 and table $\mathrm{C}_{1}$ (in Appendix C) present the same descriptive statistics as table 2 for the time series of volatility residuals and log volatilities, respectively. Comparing tables 2 and $\mathrm{C}_{1}$, it is worth noting how the logarithmic transformation effectively encourages normality in terms of skewness and kurtosis. As expected, table 3 indicates that the time series of volatility shocks are centered on zero and present significantly lower levels of skewness and kurtosis. Moreover, the autocorrelations are significantly reduced, remaining, however, positive and large for the shortest lags.

Descriptive statistics of the annualized volatilities for the period 2013-6 to 2015-12

\begin{tabular}{|c|c|c|c|c|c|c|c|c|c|c|c|}
\hline \multirow[b]{2}{*}{ Countries } & \multirow[b]{2}{*}{ Mean } & \multirow[b]{2}{*}{ Median } & \multirow[b]{2}{*}{ Min } & \multirow[b]{2}{*}{ Max } & \multirow[b]{2}{*}{ Std } & \multirow[b]{2}{*}{ Skewness } & \multirow[b]{2}{*}{ Kurtosis } & \multicolumn{4}{|c|}{ Autocorrelation } \\
\hline & & & & & & & & Lag 1 & Lag 5 & Lag 10 & $\operatorname{Lag} 20$ \\
\hline \multicolumn{12}{|l|}{ North America } \\
\hline Canada & $10.6 \%$ & $9.5 \%$ & $1.9 \%$ & $73.3 \%$ & $5.7 \%$ & 3.22 & 24.34 & 0.45 & 0.36 & 0.19 & 0.16 \\
\hline United States & $9.0 \%$ & $7.9 \%$ & $2.0 \%$ & $88.3 \%$ & $5.8 \%$ & 5.31 & 59.28 & 0.46 & 0.21 & 0.10 & 0.05 \\
\hline \multicolumn{12}{|l|}{ Europe } \\
\hline Austria & $8.8 \%$ & $7.8 \%$ & $1.8 \%$ & $48.9 \%$ & $4.6 \%$ & 2.77 & 15.51 & 0.25 & 0.15 & 0.13 & 0.04 \\
\hline Belgium & $8.0 \%$ & $7.2 \%$ & $1.5 \%$ & $46.3 \%$ & $4.0 \%$ & 2.73 & 15.91 & 0.30 & 0.14 & 0.08 & 0.06 \\
\hline France & $9.5 \%$ & $8.4 \%$ & $2.2 \%$ & $54.2 \%$ & $5.0 \%$ & 2.43 & 12.29 & 0.34 & 0.21 & 0.11 & 0.09 \\
\hline Germany & $9.7 \%$ & $8.8 \%$ & $2.9 \%$ & $54.5 \%$ & $5.0 \%$ & 2.23 & 11.34 & 0.40 & 0.23 & 0.13 & 0.13 \\
\hline Italy & $12.0 \%$ & $10.9 \%$ & $3.6 \%$ & $46.6 \%$ & $5.5 \%$ & 2.00 & 6.40 & 0.34 & 0.20 & 0.11 & 0.07 \\
\hline Netherlands & $8.1 \%$ & $7.2 \%$ & $1.8 \%$ & $63.9 \%$ & $4.5 \%$ & 3.86 & 36.92 & 0.38 & 0.22 & 0.14 & 0.12 \\
\hline Spain & $11.1 \%$ & $10.1 \%$ & $2.8 \%$ & $49.6 \%$ & $5.5 \%$ & 1.97 & 6.58 & 0.34 & 0.16 & 0.07 & 0.07 \\
\hline Sweden & $9.4 \%$ & $8.5 \%$ & $2.6 \%$ & $49.0 \%$ & $4.7 \%$ & 2.58 & 12.87 & 0.38 & 0.18 & 0.07 & 0.08 \\
\hline Switzerland & $7.6 \%$ & $6.8 \%$ & $1.8 \%$ & $49.9 \%$ & $4.0 \%$ & 3.30 & 23.12 & 0.37 & 0.16 & 0.13 & 0.13 \\
\hline United Kingdom & $8.4 \%$ & $7.7 \%$ & $1.8 \%$ & $44.9 \%$ & $4.2 \%$ & 2.66 & 13.87 & 0.42 & 0.24 & 0.12 & 0.10 \\
\hline \multicolumn{12}{|l|}{ Asia-Pacific } \\
\hline Australia & $9.0 \%$ & $8.0 \%$ & $1.2 \%$ & $46.3 \%$ & $4.6 \%$ & 2.23 & 10.05 & 0.41 & 0.32 & 0.26 & 0.18 \\
\hline China & $10.6 \%$ & $9.3 \%$ & $2.4 \%$ & $97.2 \%$ & $6.4 \%$ & 5.14 & 56.13 & 0.50 & 0.19 & 0.11 & 0.12 \\
\hline Hong Kong & $8.1 \%$ & $7.1 \%$ & $2.1 \%$ & $81.1 \%$ & $5.0 \%$ & 6.15 & 75.66 & 0.40 & 0.17 & 0.10 & 0.07 \\
\hline Japan & $8.2 \%$ & $7.2 \%$ & $2.3 \%$ & $48.5 \%$ & $4.3 \%$ & 2.43 & 13.22 & 0.52 & 0.31 & 0.19 & 0.13 \\
\hline Singapore & $7.2 \%$ & $6.4 \%$ & $1.5 \%$ & $53.4 \%$ & $4.2 \%$ & 4.15 & 31.81 & 0.44 & 0.21 & 0.16 & 0.11 \\
\hline \multicolumn{12}{|l|}{ Global } \\
\hline First PC & $18.8 \%$ & $17.0 \%$ & $8.0 \%$ & $131.2 \%$ & $8.6 \%$ & 4.58 & 46.30 & 0.49 & 0.23 & 0.11 & 0.10 \\
\hline
\end{tabular}


To ease comparison of the distributions of volatility across markets, figure 4 depicts the violin-plots for the annualized data, sorting the economies by their means (descending order). The largest mean volatilities are found in Italy $(12.0 \%)$ and Spain $(11.1 \%)$ while the lowest correspond to Singapore $(7.2 \%)$ and Switzerland $(7.6 \%)$. Moreover, the distributions of volatilities for China, US and Hong Kong are the most asymmetric ones with skewness coefficients of 6.15, 5.31 and 5.14, respectively.

Descriptive statistics of the volatility residuals for the period 2013-6 to 2015-12

\begin{tabular}{|c|c|c|c|c|c|c|c|c|c|c|c|}
\hline \multirow[b]{2}{*}{ Countries } & \multirow[b]{2}{*}{ Mean } & \multirow[b]{2}{*}{ Median } & \multirow[b]{2}{*}{ Min } & \multirow[b]{2}{*}{ Max } & \multirow[b]{2}{*}{ Std } & \multirow[b]{2}{*}{ Skewness } & \multirow[b]{2}{*}{ Kurtosis } & \multicolumn{4}{|c|}{ Autocorrelation } \\
\hline & & & & & & & & $\operatorname{Lag} 1$ & Lag 5 & Lag 10 & Lag 20 \\
\hline \multicolumn{12}{|l|}{ North America } \\
\hline Canada & 0.00 & 0.02 & -2.40 & 2.52 & 0.67 & -0.05 & 0.52 & 0.25 & 0.21 & 0.15 & 0.02 \\
\hline United States & 0.00 & 0.02 & -2.33 & 2.62 & 0.55 & -0.18 & 1.01 & 0.24 & 0.15 & 0.11 & 0.00 \\
\hline \multicolumn{12}{|l|}{ Europe } \\
\hline Austria & 0.00 & 0.00 & -2.36 & 2.44 & 0.63 & -0.07 & 1.27 & 0.11 & 0.04 & 0.08 & 0.06 \\
\hline Belgium & 0.00 & 0.02 & -2.67 & 2.17 & 0.55 & -0.13 & 1.13 & 0.14 & 0.13 & 0.06 & 0.09 \\
\hline France & 0.00 & 0.01 & -1.73 & 1.90 & 0.42 & 0.04 & 1.07 & 0.27 & 0.20 & 0.16 & 0.09 \\
\hline Germany & 0.00 & 0.00 & -1.68 & 1.21 & 0.43 & -0.16 & 0.41 & 0.30 & 0.30 & 0.23 & 0.15 \\
\hline Italy & 0.00 & -0.04 & -1.51 & 1.65 & 0.46 & 0.25 & 0.31 & 0.26 & 0.23 & 0.19 & 0.10 \\
\hline Netherlands & 0.00 & 0.01 & -1.73 & 1.28 & 0.43 & -0.27 & 0.60 & 0.24 & 0.13 & 0.09 & 0.08 \\
\hline Spain & 0.00 & -0.01 & -1.27 & 1.54 & 0.45 & -0.04 & 0.14 & 0.22 & 0.07 & 0.15 & 0.05 \\
\hline Sweden & 0.00 & 0.01 & -1.99 & 1.66 & 0.47 & -0.07 & 1.09 & 0.08 & 0.06 & 0.04 & 0.03 \\
\hline Switzerland & 0.00 & 0.00 & -1.69 & 2.58 & 0.46 & 0.29 & 1.86 & 0.19 & 0.05 & -0.06 & -0.01 \\
\hline United Kingdom & 0.00 & 0.00 & -1.79 & 1.60 & 0.43 & -0.06 & 0.97 & 0.14 & 0.06 & 0.07 & -0.05 \\
\hline \multicolumn{12}{|l|}{ Asia-Pacific } \\
\hline Australia & 0.00 & 0.03 & -2.46 & 1.74 & 0.53 & -0.24 & 0.88 & 0.12 & 0.06 & 0.14 & 0.04 \\
\hline China & 0.00 & -0.01 & -1.90 & 2.61 & 0.66 & 0.04 & 0.25 & 0.31 & 0.22 & 0.19 & 0.14 \\
\hline Hong Kong & 0.00 & 0.01 & -2.21 & 2.65 & 0.64 & 0.00 & 0.51 & 0.36 & 0.23 & 0.20 & 0.17 \\
\hline Japan & 0.00 & 0.01 & -2.29 & 1.84 & 0.61 & -0.26 & 0.15 & 0.32 & 0.27 & 0.22 & 0.17 \\
\hline Singapore & 0.00 & 0.03 & -2.22 & 3.18 & 0.68 & -0.06 & 0.78 & 0.29 & 0.29 & 0.21 & 0.22 \\
\hline
\end{tabular}

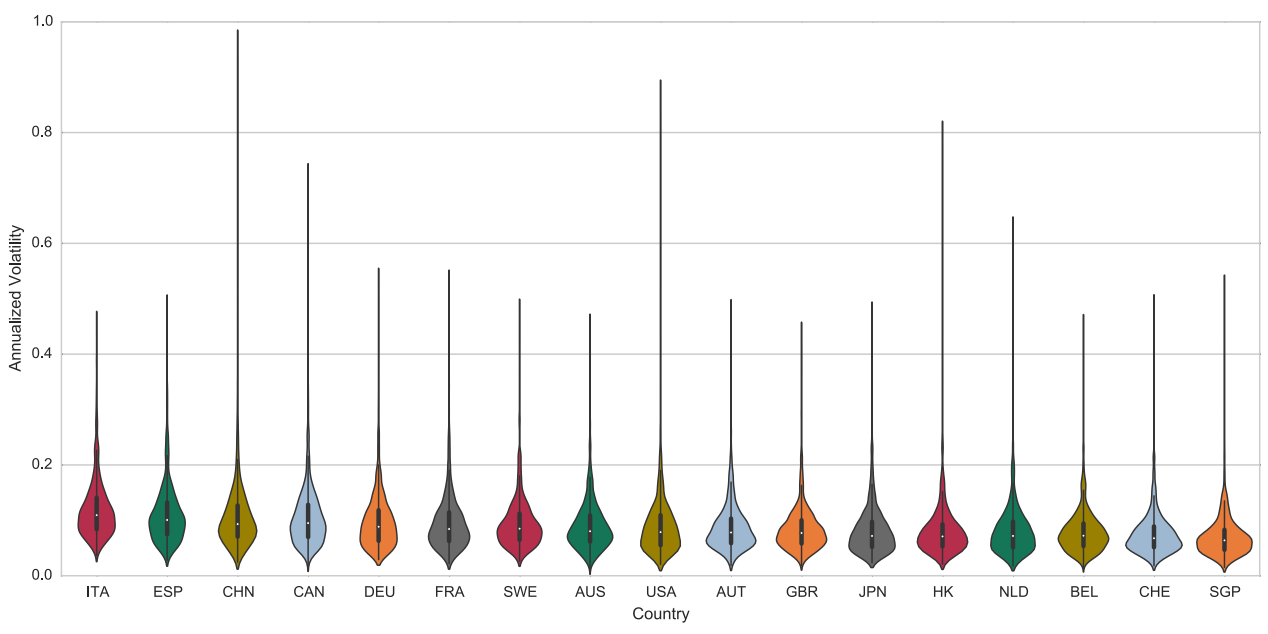

Violin-plots for the annualized volatilities corresponding to the set of ETFs included in the sample during the period Jun-2013 to Dec-2015. Countries are sorted by mean volatility. The mean volatilities are represented by white dot inside the $25-75 \%$ range represented by black bars for each distribution. 


\subsection{Describing the International Volatility Network}

A graphical representation of $\Phi^{U}$ is provided by figure 5 where the size of the nodes are scaled by their weighted degree while the width of the links are proportional to the link's weight.

The undirected International Volatility Network

FIGURE 5

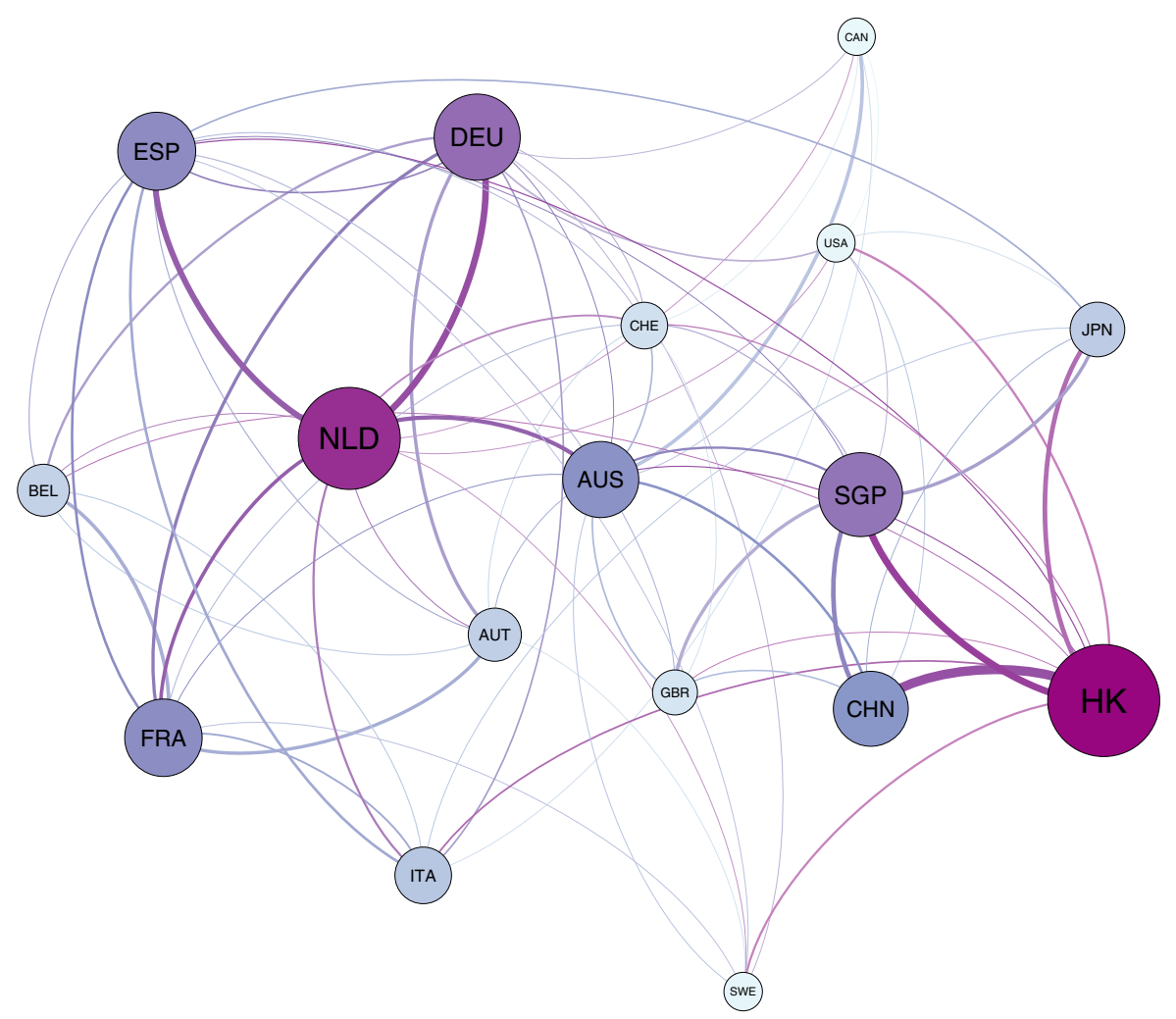

Graphical representation of the $\Phi^{U}$. The sizes of the nodes correspond to their weighted degree and the widths of the links are proportional to the elements of the upper panel in table 4.

The body of table 4 reports the output of the estimation process, say the adjacency matrix of $\Phi^{D}$, where the rows and columns are grouped by geographic regions. Moreover, the middle part of this table reports the column's average of the off-diagonal coefficients of the adjacency matrix differentiating between the impacts inside and outside of the corresponding geographic area. These quantities serve as broad indicators of the country's relevance in the network. 


\begin{tabular}{|c|c|c|c|c|c|c|c|c|c|c|c|c|c|c|c|c|c|c|}
\hline North America & & CAN & USA & AUT & BEL & FRA & DEU & ITA & NLD & ESP & SWE & $\mathrm{CHE}$ & GBR & AUS & $\mathrm{CHN}$ & HK & JPN & SGP \\
\hline Canada & CAN & 0.18 & - & - & - & - & - & - & 0.04 & - & - & - & - & 0.01 & - & - & - & - \\
\hline United States & USA & 0.02 & 0.17 & - & - & - & - & - & - & - & - & - & - & - & 0.00 & - & 0.02 & 0.01 \\
\hline \multicolumn{19}{|l|}{ Europe } \\
\hline Austria & AUT & - & - & - & - & - & - & - & - & - & - & - & - & - & - & - & - & - \\
\hline Belgium & BEL & - & - & 0.06 & 0.07 & 0.10 & 0.05 & - & - & - & - & - & - & - & - & - & - & - \\
\hline France & FRA & 0.01 & - & 0.00 & 0.02 & 0.15 & 0.05 & 0.08 & 0.07 & 0.04 & 0.02 & - & 0.01 & 0.01 & - & - & - & - \\
\hline Germany & DEU & 0.01 & 0.04 & 0.05 & 0.04 & 0.05 & 0.21 & - & 0.12 & 0.03 & 0.01 & 0.00 & - & 0.00 & - & - & - & - \\
\hline Italy & ITA & 0.03 & - & - & 0.07 & - & 0.08 & 0.19 & 0.09 & 0.05 & - & - & - & - & - & - & 0.06 & - \\
\hline Netherlands & NLD & 0.03 & - & 0.03 & - & 0.09 & 0.06 & 0.02 & 0.16 & 0.05 & 0.01 & 0.06 & - & 0.06 & - & - & - & - \\
\hline Spain & ESP & - & - & 0.03 & 0.05 & 0.00 & 0.01 & 0.08 & 0.13 & 0.16 & 0.01 & - & 0.06 & - & - & - & 0.06 & - \\
\hline Sweden & SWE & - & - & - & - & - & - & - & - & - & - & - & - & - & - & - & - & - \\
\hline Switzerland & CHE & - & - & 0.01 & - & - & - & - & - & - & - & 0.11 & - & - & - & - & - & - \\
\hline United Kingdom & GBR & - & - & - & - & - & - & - & - & - & - & - & 0.06 & - & - & - & - & - \\
\hline \multicolumn{19}{|l|}{ Asia-Pacific } \\
\hline Australia & AUS & 0.08 & 0.02 & - & - & - & - & - & 0.06 & - & 0.04 & 0.05 & 0.05 & 0.07 & 0.07 & 0.02 & - & 0.08 \\
\hline China & $\mathrm{CHN}$ & - & - & - & - & - & - & - & - & - & - & - & 0.04 & - & 0.12 & 0.24 & - & 0.12 \\
\hline Hong Kong & HK & - & 0.05 & - & 0.00 & - & - & 0.05 & - & - & 0.05 & 0.02 & - & - & 0.09 & 0.23 & 0.11 & 0.14 \\
\hline Japan & JPN & - & 0.03 & - & 0.03 & - & - & 0.02 & - & - & - & - & - & - & 0.05 & 0.08 & 0.25 & 0.06 \\
\hline Singapore & SGP & - & 0.05 & 0.01 & - & - & - & - & - & 0.09 & 0.04 & 0.10 & 0.17 & - & 0.04 & 0.13 & 0.10 & 0.25 \\
\hline
\end{tabular}

Mean Coefficient (off diagonal elements)

\begin{tabular}{|c|c|c|c|c|c|c|c|c|c|c|c|c|c|c|c|c|c|}
\hline All countries & 0.01 & 0.01 & 0.01 & 0.01 & 0.02 & 0.02 & 0.02 & 0.03 & 0.02 & 0.01 & 0.01 & 0.01 & 0.02 & 0.02 & 0.03 & 0.02 & 0.03 \\
\hline Own region & 0.01 & 0.01 & 0.01 & 0.02 & 0.03 & 0.03 & 0.02 & 0.04 & 0.03 & 0.00 & 0.00 & 0.00 & 0.02 & 0.06 & 0.08 & 0.04 & 0.07 \\
\hline Other regions & 0.01 & 0.01 & 0.00 & 0.00 & 0.00 & 0.00 & 0.01 & 0.01 & 0.01 & 0.01 & 0.01 & 0.02 & 0.02 & 0.00 & 0.01 & 0.01 & 0.02 \\
\hline
\end{tabular}

Assortativity Coefficient (Nodes gruoped by geographic area)

\begin{tabular}{ll}
\hline Directed IVN & 0.27 \\
\hline Undirected IVN & 0.19
\end{tabular}

Each row from the upper panel of this table corresponds to a row-by-row estimation of equation (1) as stated in equation (5). Adaptive Lasso estimators are obtained by means of 3-folds cross validation where the initial coefficients come from OLS estimators. A detailed description of the estimation methodology is provided by Appendix A. The bottom panel of this table quantifies the column-wise average from the upper panel discarding the coefficients from the main diagonal. The assortativity coefficient is computed following Newman (2003) as described in section 3.1. This coefficient is provided for the directed and undirected versions of the International Volatility Network. Countries are sorted by continents in the rows and columns of the table.

The markets with the largest mean impact on the rest of the system are the Netherlands, Hong Kong and Singapore (0.03) where the effects from the latter two are mostly explained through their influence on the Chinese economy (0.24 and 0.12). In a second order of magnitude, Asian economies like China and Japan also present sizable effects on other markets. Regarding European economies, countries like France, Germany, Italy, Spain and the United Kingdom assume critical roles as volatility spreaders in the IVN. From the opposite perspective, Austria, Sweden and the United Kingdom comprise the most exogenous nodes in the system since the estimation methodology fails to identify any effects upon them arising from other nodes in the network. 
A detailed inspection of table 4 shows that Germany (in Europe) and Hong Kong and China (in Asia) strongly affect most of the economies in their respective continents. In particular, the German market affects 5 out of 9 European countries with average non-null coefficient of 0.05 while Hong Kong and China impact on each of the remaining Asian markets with an average non-null coefficient of 0.11 and 0.06 . The case of the Netherlands is particularly interesting since its average impact is stronger than Germany's, but only 4 out of 9 European countries are affected by its volatility surprises. A complete quantification of the in- and out-degrees in $\Phi^{D}$ is provided in table 5 where qualitatively similar conclusions can be drawn. In a different context, Hameed et al. (2015) defines firms whose fundamentals are highly correlated with those of peer firms as "bellwether firms". They show that when financial analysts revise a bellwether firm's earnings forecast, it changes the prices of other firms significantly; however, the reverse effect is not supported by the data. For the particular case analyzed in this study, countries like Germany and Hong Kong might resemble "bellwether countries" in the spirit of Hameed et al. (2015). It seems interesting to determine the extent to which the relative investor's coverage/ attention is a plausible explanation for this empirical finding. A deeper investigation in this regard is required and I leave it as future research line.

\begin{tabular}{|c|c|c|c|c|c|}
\hline \multirow[b]{2}{*}{ North America } & & \multicolumn{4}{|c|}{ Directed } \\
\hline & & In Degree & $\begin{array}{l}\text { In Degree } \\
\text { (Weight) }\end{array}$ & Out Degree & $\begin{array}{c}\text { Out Degree } \\
\text { (Weight) }\end{array}$ \\
\hline Canada & CAN & 2 & 0.051 & 6 & 0.179 \\
\hline United States & USA & 4 & 0.048 & 5 & 0.187 \\
\hline \multicolumn{6}{|l|}{ Europe } \\
\hline Austria & AUT & 0 & - & 7 & 0.196 \\
\hline Belgium & BEL & 3 & 0.217 & 6 & 0.206 \\
\hline France & FRA & 10 & 0.316 & 4 & 0.246 \\
\hline Germany & DEU & 10 & 0.347 & 5 & 0.251 \\
\hline Italy & ITA & 6 & 0.383 & 5 & 0.254 \\
\hline Netherlands & NLD & 9 & 0.418 & 6 & 0.512 \\
\hline Spain & ESP & 9 & 0.429 & 5 & 0.273 \\
\hline Sweden & SWE & 0 & - & 7 & 0.179 \\
\hline Switzerland & $\mathrm{CHE}$ & 1 & 0.012 & 5 & 0.237 \\
\hline United Kingdom & GBR & 0 & - & 5 & 0.327 \\
\hline \multicolumn{6}{|l|}{ Asia-Pacific } \\
\hline Australia & AUS & 9 & 0.467 & 4 & 0.083 \\
\hline China & $\mathrm{CHN}$ & 3 & 0.403 & 5 & 0.252 \\
\hline Hong Kong & HK & 8 & 0.510 & 4 & 0.458 \\
\hline Japan & JPN & 6 & 0.264 & 5 & 0.336 \\
\hline Singapore & SGP & 9 & 0.722 & 5 & 0.408 \\
\hline
\end{tabular}

A thorough examination of table 4 also permits identification of two features of the data that call for further analysis and explanation. Firstly, the average impact coefficient towards other countries in the same geographic region (the column-wise av- 
erage of the row "own region" in table 4 is 0.032) is more than three times higher than towards countries located outside the domestic area (the column-wise average of the row "other regions" in table 4 is o.010). In the same line of argument, table 4 shows that non-zero lead-lag coefficients are more frequently found between countries from the same continent than intercontinentally. In fact, when grouping countries by continent, the assortativity coefficient (reported in the bottom part of table 4) is 0.27 and 0.19 for the directed and undirected $I V N$, respectively. This evidence is consistent with a network organized in communities where countries in the same continent are tightly interconnected but weakly interconnected across continents. Secondly, it is hard to reconcile the dynamical patterns shown by the series of volatility surprises with the efficient market hypothesis. Rizova (2010) shows that the stock market returns of a country's major partner forecast the subsequent stock market return of that country and the author proposes the gradual diffusion of information hypothesis (Hong and Stein, 2007) as a plausible explanation. In this study, it is the second moment of the returns distribution, instead of the first one, that spreads strongly across countries.

The subsequent sections provide theoretical arguments explaining each of these findings with their corresponding supporting evidence. Specifically, I argue that the community structure found in the $I V N$ is consistent with the intuition of volatility shocks spreading across economically linked economies, thus encompassing fundamental information. On the other hand, the observed lead-lags of volatilities can be explained as a consequence of the gradual diffusion of information hypothesis explained by investors subjected to limited attention and home bias (Menzly and Ozbas, 2010, Cohen and Frazzini, 2008, Hong and Stein, 2007). 


\section{The Major Drivers of Volatility Spillovers}

\subsection{Why does volatility tend to spread strongly towards other countries from the same continent?}

As discussed by Strohsal and Weber (2012), market volatility has been ambiguously used in the financial literature to describe the arrival of valuable news to the market and to capture pure uncertainty. Accordingly, volatility spillovers across markets might indicate the spread of valuable information among fundamentally linked economies or the transfer of uncertainty-related shocks. The analysis below provides quantitative supports for the former intuition.

Currently, there is almost no country in the world that exists as an isolated entity. In turn, economies are linked to each other through many types of interactions; some of them are crystal-clear transactions while others are more subtle. I use export and import relationships between countries as a comprehensive proxy of their fundamental/economic association. Table 6 summarizes the information from the trade data described in section 4 regarding the value export and import flows for the period 2013-2015. The largest exporter in the sample is China (6.8 trillions) while the largest importer is the United States (6.9 trillions). The table also reports the relative weights of total exports (imports) by country to (from) other trade partners in the sample grouped by geographic regions. ${ }^{11}$ The data shows that, with the exception of the US economy, most of the value of international trade is allocated between countries from the same continent, thus indicating the strength of their economic ties. For instance, the average percentage exports from European countries to others in Europe is $49.7 \%$, representing a much higher proportion when compared to the corresponding magnitude to North America (7.8\%) and Asian (8.2\%) economies.

11 The sum of the percentage in each row is not $100 \%$ since the sample does not contain all trade partners of each country. 


\begin{tabular}{|c|c|c|c|c|c|c|c|c|c|}
\hline \multirow[b]{2}{*}{ North America } & & \multicolumn{4}{|c|}{ Export to } & \multicolumn{4}{|c|}{ Import from } \\
\hline & & Noth America & Europe & Asia Pacific & World & Noth America & Europe & Asia Pacific & World \\
\hline Canada & CAN & $76.5 \%$ & $6.8 \%$ & $7.5 \%$ & $1,341.21$ & $53.2 \%$ & $10.4 \%$ & $14.9 \%$ & $1,476.88$ \\
\hline United States & USA & $19.0 \%$ & $17.1 \%$ & $17.9 \%$ & $4,703.49$ & $14.2 \%$ & $16.1 \%$ & $27.6 \%$ & $6,857.72$ \\
\hline Avrg & & $47.7 \%$ & $12.0 \%$ & $12.7 \%$ & & $33.7 \%$ & $13.2 \%$ & $21.3 \%$ & \\
\hline \multicolumn{10}{|l|}{ Europe } \\
\hline Austria & AUT & $6.3 \%$ & $54.5 \%$ & $4.4 \%$ & 506.08 & $2.5 \%$ & $66.1 \%$ & $4.2 \%$ & 520.54 \\
\hline Belgium & BEL & $6.0 \%$ & $63.5 \%$ & $4.5 \%$ & $1,339.75$ & $8.4 \%$ & $56.5 \%$ & $8.2 \%$ & $1,281.87$ \\
\hline France & FRA & $7.3 \%$ & $53.6 \%$ & $8.0 \%$ & $1,666.21$ & $5.7 \%$ & $61.8 \%$ & $6.6 \%$ & $1,930.21$ \\
\hline Germany & DEU & $9.6 \%$ & $45.2 \%$ & $9.6 \%$ & $4,267.97$ & $4.6 \%$ & $50.1 \%$ & $9.0 \%$ & $3,438.16$ \\
\hline Italy & ITA & $8.5 \%$ & $46.4 \%$ & $6.7 \%$ & $1,506.30$ & $4.0 \%$ & $47.5 \%$ & $8.0 \%$ & $1,362.71$ \\
\hline Netherlands & NLD & $4.2 \%$ & $66.0 \%$ & $4.1 \%$ & $1,909.94$ & $7.6 \%$ & $38.7 \%$ & $17.2 \%$ & $1,685.57$ \\
\hline Spain & ESP & $4.7 \%$ & $49.7 \%$ & $4.1 \%$ & 919.94 & $3.7 \%$ & $46.6 \%$ & $7.4 \%$ & $1,011.18$ \\
\hline Sweden & SWE & $7.6 \%$ & $37.5 \%$ & $6.9 \%$ & 471.90 & $2.9 \%$ & $45.8 \%$ & $7.1 \%$ & 460.82 \\
\hline Switzerland & $\mathrm{CHE}$ & $10.5 \%$ & $38.2 \%$ & $22.8 \%$ & 958.80 & $8.5 \%$ & $60.4 \%$ & $7.7 \%$ & 847.83 \\
\hline United Kingdom & GBR & $13.5 \%$ & $42.4 \%$ & $10.7 \%$ & $1,504.21$ & $10.1 \%$ & $43.4 \%$ & $11.8 \%$ & $1,975.61$ \\
\hline Avrg & & $7.8 \%$ & $49.7 \%$ & $8.2 \%$ & & $5.8 \%$ & $51.7 \%$ & $8.7 \%$ & \\
\hline \multicolumn{10}{|l|}{ Asia-Pacific } \\
\hline Australia & AUS & $4.8 \%$ & $4.7 \%$ & $55.3 \%$ & 682.82 & $11.6 \%$ & $16.1 \%$ & $33.5 \%$ & 727.58 \\
\hline China & $\mathrm{CHN}$ & $18.5 \%$ & $12.8 \%$ & $26.1 \%$ & $6,834.42$ & $9.2 \%$ & $12.5 \%$ & $15.2 \%$ & $5,514.17$ \\
\hline Hong Kong & $\mathrm{HK}$ & $10.0 \%$ & $8.7 \%$ & $60.3 \%$ & $1,398.67$ & $5.6 \%$ & $8.3 \%$ & $61.3 \%$ & $1,591.64$ \\
\hline Japan & $J P N$ & $20.5 \%$ & $9.5 \%$ & $28.6 \%$ & $2,029.63$ & $10.7 \%$ & $9.1 \%$ & $29.9 \%$ & $2,292.55$ \\
\hline Singapore & SGP & $6.5 \%$ & $7.1 \%$ & $31.7 \%$ & $1,173.75$ & $11.0 \%$ & $12.2 \%$ & $20.3 \%$ & $1,036.42$ \\
\hline Avrg & & $12.1 \%$ & $8.6 \%$ & $40.4 \%$ & & $9.6 \%$ & $11.7 \%$ & $32.0 \%$ & \\
\hline
\end{tabular}

Percentages of Exports and Imports relative to totals values by sample countries during the years 2013-2015. Totals are measured in thousand of millons US dollars.

To continue with the analysis let us introduce another network that we call the International Trade Network (ITN), encompassing the fundamental interconnections among countries as determined by their trade links. The subsequent analysis shows that the $I V N$ is closely related to the ITN indicating that market volatility does not randomly spread from one economy to another but tends to follow the paths dictated by trade connections. More precisely, assuming that volatilities carry valuable information and that trade links are sufficient statistics of fundamental association between countries, the IVN and ITN should resemble each other closely. Otherwise, $I T N$ would be a sort of sub-network embedded into the IVN whose excess interconnectivity captures uncertainty-related links. Denoting by $X_{i j, t}$ the US value of the exports from country $i$ to country $j$ at the end of year $t$, the formal definition of the ITN is as follows ${ }^{12}$ :

12 Due to statistical issues, the value of exports reported by country $i$ to country $j$ is not exactly equal to the value of the imports reported by county j from country i. Equation (6) solves this discrepancy by averaging these two quantities. 
Definition 3: The International Trade Network is a weighted and undirected network denoted by $\Phi^{T}=\left(N, W=\left[w_{i j}\right]\right)$ where $N$ is the set of countries under analysis and $W$ is the corresponding adjacency matrix whose elements are given by equation (6).

$$
w_{i j}=\log \left(\sum_{t=2013}^{2015} \frac{\left(X_{i j, t}+X_{j i, t}\right)}{2}\right)
$$

As previously commented, the network $\Phi^{T}$ comprises information on the fundamental association between sample economies as dictated by their trade links. Since $\Phi^{T}$ is a fully connected network ${ }^{13}$, a pruning procedure is in place in order to get a simplified version of this structure. Let us denote by $\tilde{\Phi}^{T}=\left(N, \tilde{W}=\left[\tilde{w}_{i j}\right]\right)$ a network obtained by discarding links with the lowest weights from $\Phi^{T}$ up to the point at which the network remains connected. Figure 6 displays a graphical representation of $\tilde{\Phi}^{T}$ where the sizes of the node are scaled by their weighted degree while the widths of the links are proportional to $w_{i j}$. This figure makes clear the importance of Germany, China and US as fundamental players in the world trade market.

\section{The International Trade Network}

FIGURE 6

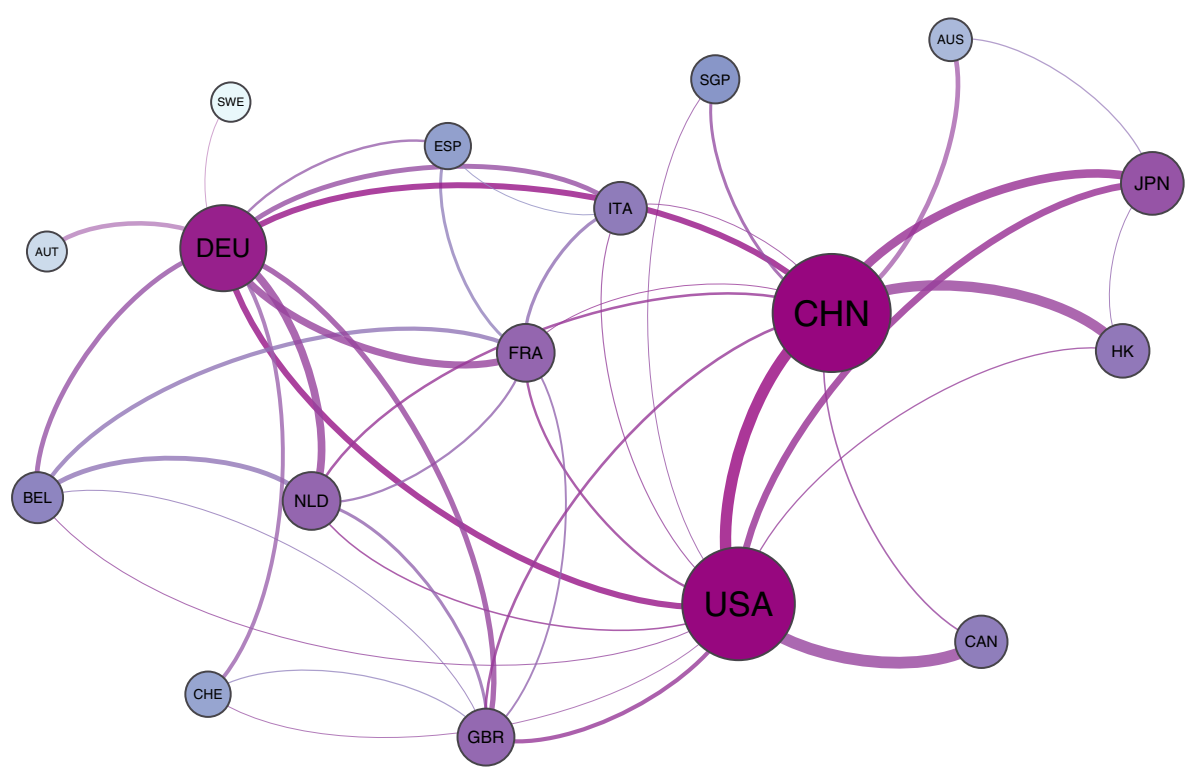

Graphical representation of $\tilde{\Phi}^{T}$. The sizes of the nodes correspond to their weighted degree and the widths of the links are proportional to $w_{i j}$.

A visual comparison between $\Phi^{T}$ and $\Phi^{U}$ is provided by figure 7 by plotting the heat maps corresponding to their adjacency matrices in the right and left panel, respectively, while sorting their rows and columns by geographic regions. A bird's-eye view allows us to detect the correspondence between the "hottest" regions across the panels of figure 7 demonstrating that the largest volatility transfers coincide with the strongest trade links.

13 A fully connected network refers to a structure where each possible link is activated. 

and the ITN
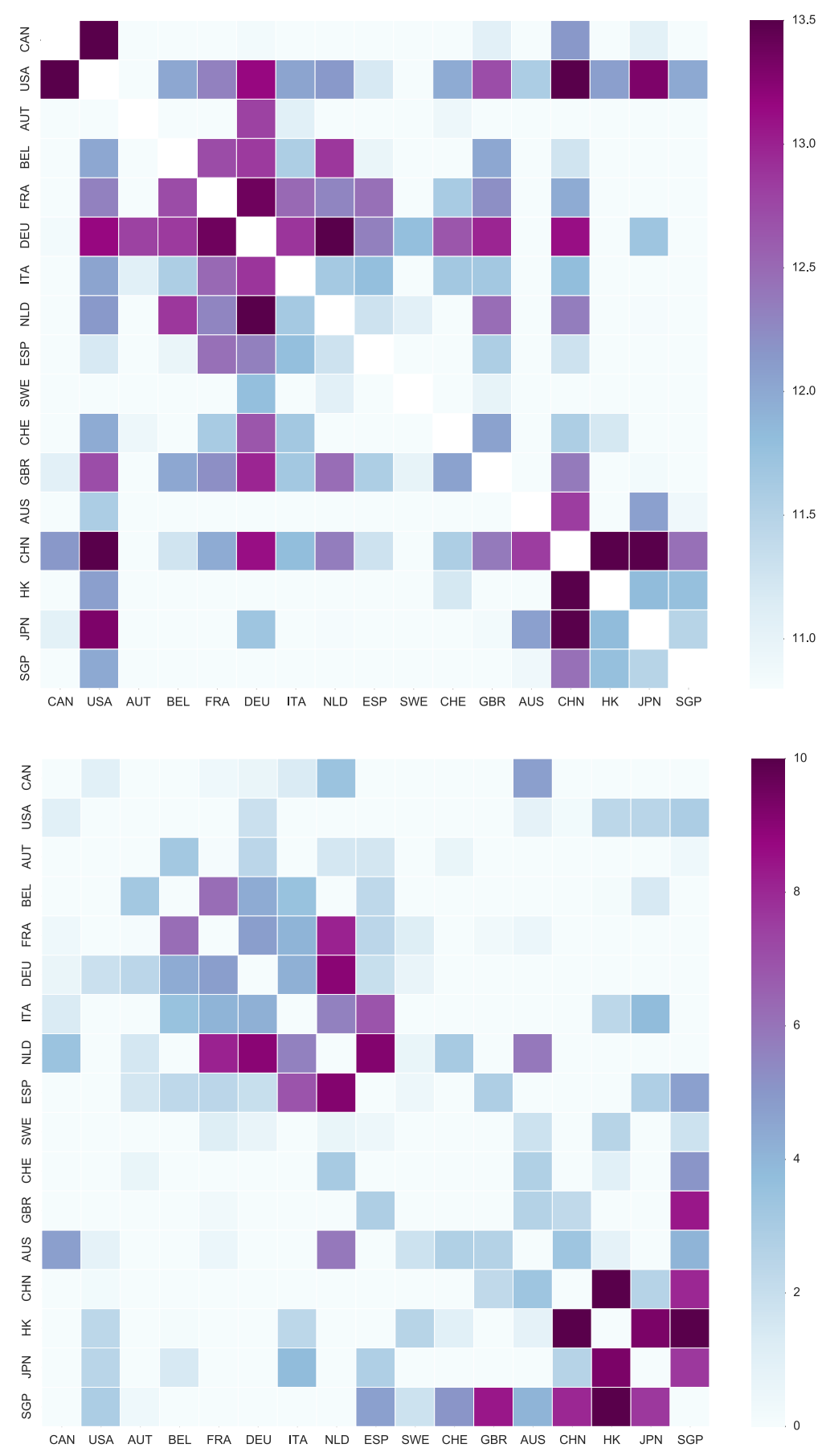

Heat-maps of the adjacency matrix of the ITN $\Phi^{T}$ (right) and of the undirected IVN $\Phi^{U}$ (left). The intensity of the colors is in accordance with color bars located alongside the corresponding heat-map. Countries are sorted by continent in the rows and columns of the graphs.

Since the IVN and the ITN contain the same set of nodes, a proper assessment of their similarity should focus on the configuration of their links. More precisely, there are two dimensions in which this configuration can be analyzed: i) by studying the correlation between the weights of the links that exist simultaneously across both networks and ii) by quantifying the likelihood of observing the amount of overlapping of links between these empirical structures. Starting from the first intuition, table 7 re- 
ports OLS estimations resulting from the regression of the non-null links' weights from $\Phi^{U}$ on the corresponding links' weights from $\Phi^{T}$. Assuming that the informational content of volatility spillover hypothesis holds, we should expect a positive and significant coefficient for the explanatory variable. Therefore, strong connections between countries as measured by trade links result in strong channels through which the volatility spreads. And this, in fact, turns out to be the case since the value of the slope coefficient is 0.546 with t-statistic of 2.245 , while the constant term is not statistically different from zero at conventional levels. Figure 8 presents the scatter plot corresponding to this regression analysis with the OLS results as a solid line.

Relationship between the weights of the links across the IVN and the ITN

\begin{tabular}{lcccc} 
& Coefficient & Stand Dev & t-value & p-value \\
\hline Cons & -2.729 & 2.744 & -0.994 & 0.324 \\
\hline Link-Weights ITN & 0.546 & 0.243 & 2.245 & 0.028 \\
\hline F-test (p-value) & 0.028 & & & \\
\hline R-square & 0.071 & & & \\
\hline Num. Observations & 68 & & & \\
\hline
\end{tabular}

OLS estimations of a regression where the dependent variable corresponds to the non-null link-weights in the IVN and the independent corresponds to the weights of the same links in the ITN. Standart erros are corrected by heteroskedasticity and autocorrelation following Newey and West (1987).

\section{Relationship between the weights of the links across the IVN and the ITN FIGURE 8}

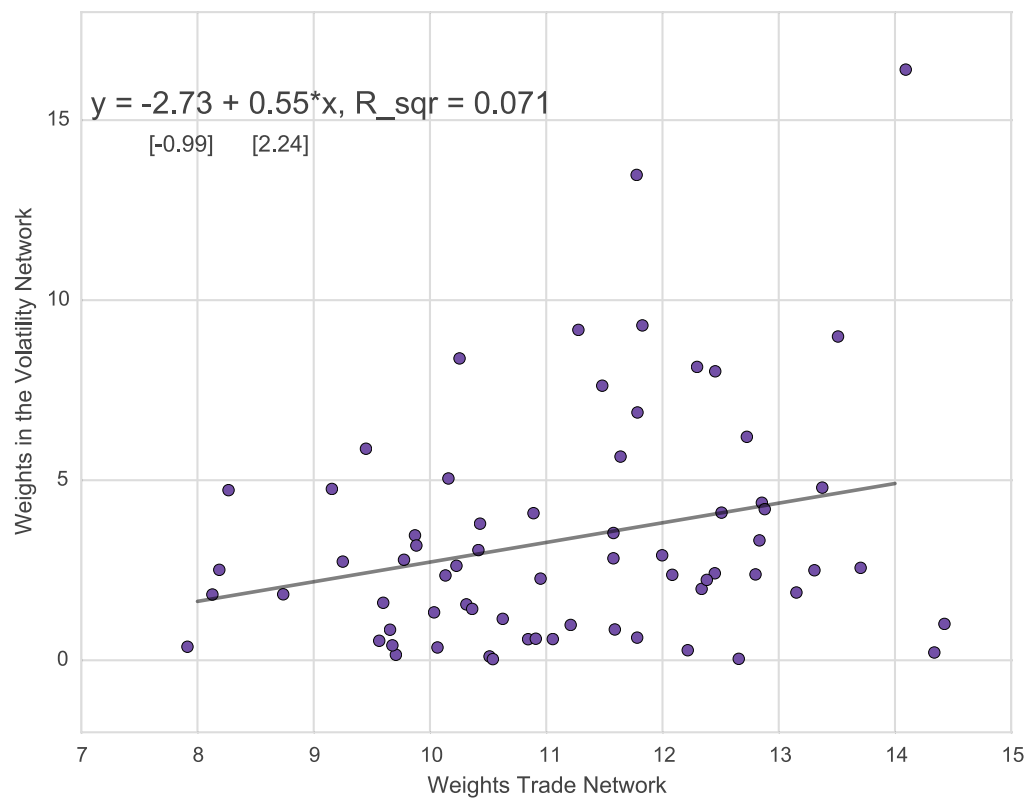

Scatter plot between the non-null links' weights in $\Phi^{U}$ against the corresponding links' weights in $\Phi^{T}$. Solid line correspond to the estimation results reported in table 7.

Next, I empirically test the second dimension in which the network configurations can differ by looking at links' overlapping across the structures. As previously suggested, the hypothesis of informational content of volatility spillovers is consistent with a substantial and non-random overlapping of links between the IVN and the ITN. To formally test this intuition the following test is proposed with the aim of determining the 
likelihood of such overlapping. I start by creating two random networks (Erdös-Renyi framework), each with the same node-size and link-size as for the empirical IVN and ITN. Then, I identify the connections that simultaneously exist in both of these random replications giving rise to the so-called intersectional network. I repeat this procedure 10,000 times and compute the proportion of cases in which the links-size of the intersectional network is equal to or greater than the amount of links' overlapping arising from the empirical counterparts. Since the Erdös-Renyi framework provides networks made by chance, this proportion resembles a p-value in a traditional hypothesis test where the null hypothesis refers to non-systematic overlapping of links.

The results from this test on links' overlapping are reported in table 8, considering not only the complete versions of IVN and ITN but also applying the same methodology to the sub-networks comprising only countries from the same continent. The densities of $I V N$ and $I T N$ are $50 \%$ and $32 \%$, respectively, while the link-sizes are 68 and 43 . The intersectional network contains 26 links leading to a density of $19 \%$. The last column of table 8 reports the p-values of the overlapping test discussed above and indicates that only $7 \%$ of the 10,000 random replications show an amount of overlapping links equal to or greater than 26 for the complete case, thus rejecting the null-hypothesis at $10 \%$ significance. The results of similar experiments on the continental networks are also shown in table 8 where the null-hypothesis is not rejected at conventional levels. However, I disregard this evidence since it is a direct consequence of the intense interconnectivity between the counties in these substructures leading to large network densities. In other words, considering the case when either the (continental) IVN or the ITN is fully connected, the resulting intersectional networks derived from random replications will have the same amount of links as those derived from the less dense one, undermining the informational content of the test. ${ }^{14}$ On the other hand, the intense interlinkages in this continental networks reinforce the evidence of strong interconnectivity among the countries from the same geographical area.

Non-random link ovelapping between the IVN and the ITN

\begin{tabular}{lcccccccc} 
& & \multicolumn{2}{c}{ IVN } & \multicolumn{2}{c}{ ITN } & \multicolumn{3}{c}{ Intersectional Network } \\
\cline { 2 - 9 } & Nodes & Links & Density & Links & Density & Links & Density & p-value \\
\hline All & 17 & 68 & $50 \%$ & 43 & $32 \%$ & 26 & $19 \%$ & 0,07 \\
\hline North America & 2 & 1 & $100 \%$ & 1 & $100 \%$ & 1 & $100 \%$ & 1,00 \\
\hline Europe & 10 & 28 & $62 \%$ & 19 & $42 \%$ & 14 & $31 \%$ & 0,15 \\
\hline Asia-Pacific & 5 & 9 & $90 \%$ & 6 & $60 \%$ & 5 & $50 \%$ & 1,00 \\
\hline
\end{tabular}

Columns Nodes, Links and Density reports the node-size, link-size and density for the corresponding networks. The intersectional network results from the indentification of the links that simultaneously appear in the IVN and in the ITN. On the rows, All accounts for the networks including every node in the sample. North America, Europe and Asia-Pacific correspond to networks where only countries from these continents are considered. Column p-value reports the significance of the hypothesis test where HO refers to non-systematic link-overlapping between the corresponding IVN and the ITN.

Finally, the upper panel of figure 9 presents the scatterplot between the rankings of eigenvector centralities in IVN (x-axis) and in ITN (y-axis). Additionally, the middle and bottom panels of the same figure plot the distribution of these indices of influ-

14 The identification of the links' overlapping between a fully connected network and a less connected structure will always provide the same results. 
ence for both structures. Assuming that the fundamental information spillover hypothesis holds, a similar degree of countries' influence should be observed across the networks. In accordance with the upper panel of figure 9, there is mild evidence supporting this fact. The Kendall rank-correlation is 0.12 , however it is not statistically significant. From the bottom panel of figure 9, we observe the most influential economies affecting international trades are the US, China and Germany in accordance with figure 6 . From the middle panel of figure 9 we note that the most central nodes in the IVN correspond to the Asian markets (e.g. Hong Kong, Singapore, China and Japan). It should be remarked the disproportionate influence of Asian economies as volatility spreaders versus their influence as trade partners by noting their tendency to lie below the $45^{\circ}$ line in the upper panel of figure 9. This observation calls for further study and I leave it as a future research line.

\section{Centrality of countries in the IVN and in the ITN}
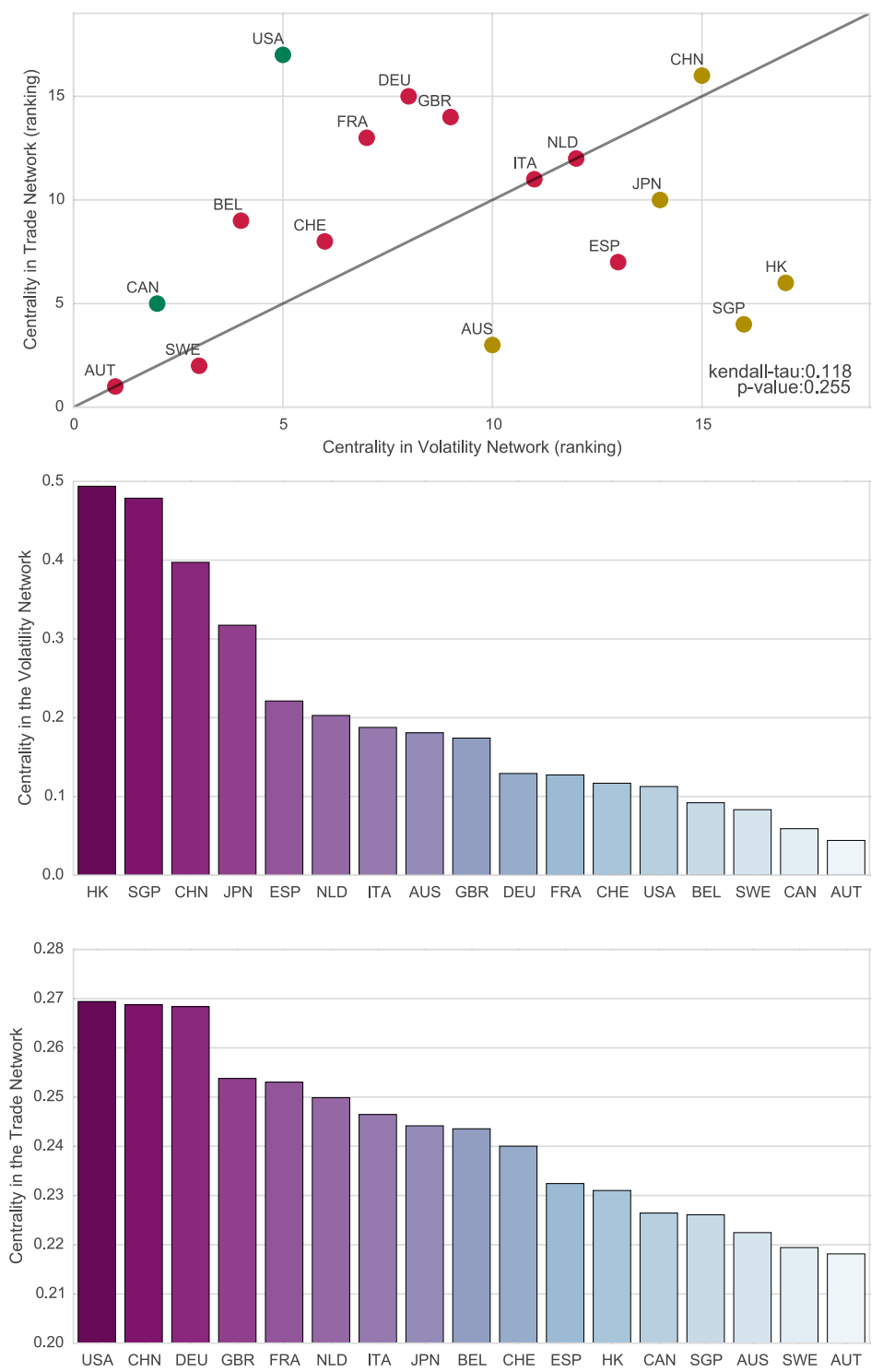

Scatter plot between the ranks of eigenvector centrality of countries in $\Phi^{U}$ against the corresponding eigenvector centrality in $\Phi^{T}$ (upper panel). The p-value for the Kendall rank correlation is derived from a one-tailed test where $H_{0}: \tau \leq 0$ against $H_{0}: \tau>0$. The distributions of eigenvector centrality of countries in $\Phi^{U}$ and in $\Phi^{T}$ are represented in the middle and bottom panels, respectively. 


\subsection{Why does volatility spread with lags?}

In accordance with the analysis provided in section 6, there is strong evidence showing substantial cross-predictability (lead-lags) of volatilities, notably inside the same continent. The following analysis exploits the Google search database (see section 4) to find empirical support for the hypothesis of gradual diffusion of information across investors that are subject to limited attention and home bias as a plausible explanation of this finding.

As argued by Hong and Stein (2007), there are many reasons to explain why relevant information reaches some investors before others giving rise to the so-called gradual diffusion of information (e.g., technology of information distribution or investors' area of specialization). When this hypothesis holds, those investors who are favored by this informational advantage would trade in accordance to their new valuations and benefit by buying or selling securities from/to the rest of the investors in the market. Huberman and Regev (2001) discuss the case of EntreMed, a biotechnology firm, as a clear example in this regard. On May 4, 1998, its price shows a striking increase of $333 \%$ (from $\$ 12$ in the previous trading day up to a peak of $\$ 52$ on the day in question) after a front-page article in New York Times was published the day before about a recent innovation in cancer treatment. What is remarkable in this story is that there was no essential news in the New York Times article since these results had already been published by Nature (a scientific journal) five months earlier. Despite price movement being observed at the time of Nature's publication, the intensity of that movement was not as intense as that following the New York Times publication. There are two ways to interpret this evidence: $i$ ) investors are fully rational agents facing different information acquisition costs (access to scientific news imposes large costs on agents with no technical background in the subject) or ii) investors are subject to limited attention, thus partially disregarding all publicly available information while concentrating on a constrained informational set.

A direct consequence of the gradual diffusion of information hypothesis in the context of several securities is the cross-predictability of returns across fundamentally connected investment vehicles. Cohen and Frazzini (2008) finds that returns of important customers of a firm can forecast the returns of that firm and Menzly and Ozbas (2010) document similar results at industry level. Hou (2007) reports significant lead-lags between big firms and small firms, particularly inside the same industry, as a phenomenon generated by the gradual diffusion of information. In a similar fashion, Rizova (2010) presents evidence supporting the cross-predictability of returns between market indices of countries that are strongly linked through international trade relationships. Despite this evidence on returns' cross-predictability, to my knowledge, no empirical studies consider the gradual diffusion of information as the fundamental mechanism behind the spillover of volatility among countries. More precisely, my argument goes as follows. There is substantial evidence indicating the existence of home bias for domestic investors (French and Poterba, 1991, Faruqee, Li, and Yan, 2004, Van Nieuwerburgh and Veldkamp, 2009) which sets the basis for the gradual diffusion of information. These specialized investors in domestic assets closely follow the news from home countries while reacting with delays to innovations taking place in other economically related countries. The fundamental reason behind 
this lagged response is the limited attention paid by domestic investors to foreign shocks.

As discussed in section 4, I rely on Google search data from a domestic country on the market index of a foreign country as a proxy of investors' "cross attention". Da, Engelberg, and Gao (2011) is the first study analyzing this source of information for the case of US-listed firms finding that the increase of the search intensity upon a given stock can predict future returns for that securities. I exploit this type of data by analyzing how current domestic attention paid to the market volatility of a related economy exhibits delayed reactions to foreign volatility innovations. To illustrate the analysis, figure 10 plots the time series of the volatility shocks for the US, German and Japanese markets as defined by equation (4) jointly with the time series of the Google Search Indices of these economies on the Chinese market index $\left(G S I_{t, i \rightarrow C H N}\right.$ for $\left.i=U S, D E U, J P N\right)$ around Chinese Black Monday (August 24, 2015). From the analysis of this figure, it is clear that the attention to the Chinese market starts to increase even before the occurrence of Chinese shock.. More interestingly, the series of investors' attention reach their maximum one day after Chinese Black Monday and remain higher afterwards.

\section{Delayed reaction of domestic attention to the Chinese Black Monday}
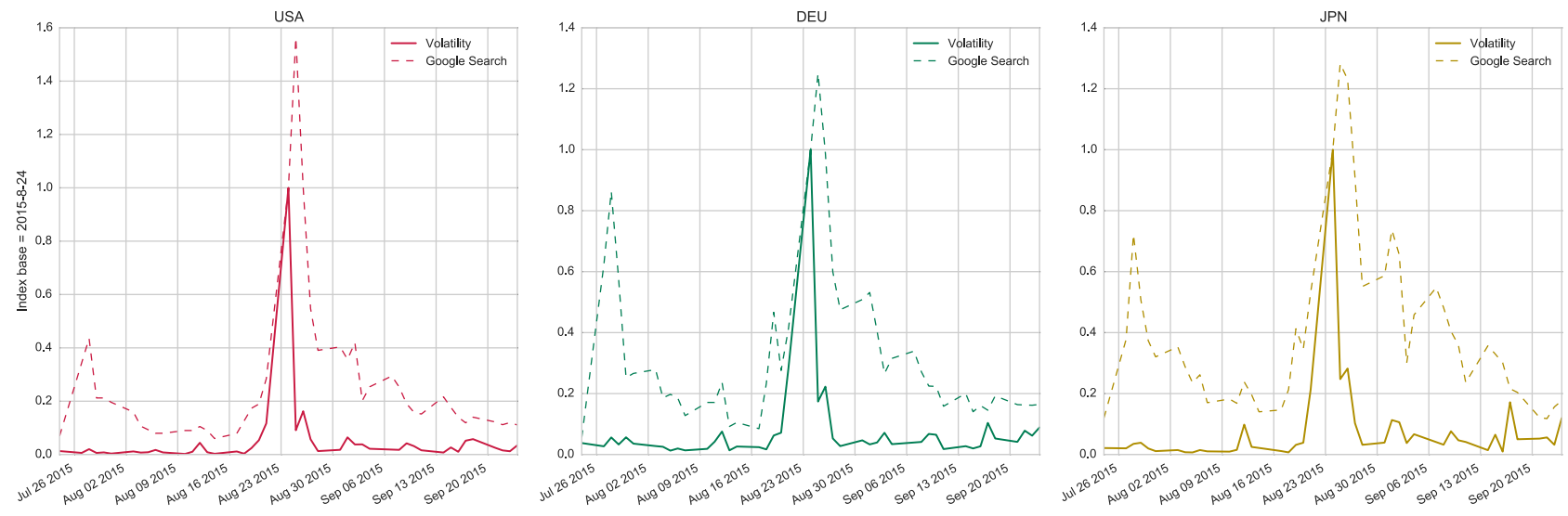

Comparison between volatility shocks (solid line) arising in the US (left panel), German (middle panel) and Japanese (right panel) markets and the corresponding Google Search Index on the Chinese market (dotted line) arising in those economies. Variables are standardized to assumed value 1 on August 24, 2015.

To formally test the gradual diffusion of information hypothesis, the entire empirical analysis is divided into two stages that are graphically described in figure 11. In the first stage I test the effects of domestic attention to unexpected volatility shocks arising in the markets of major trade partners. These correspond to the first set of arrows pointing from the left-most grey squares, representing foreign markets, towards the black circle representing the attention of domestic investors. In the second stage I quantify the effects of domestic attention paid to the domestic market as well as to the markets of major trade partners on the performance of the domestic market. This stage is represented in figure 11 by the arrow pointing from the black circle to the right-most grey square corresponding to the domestic market. 


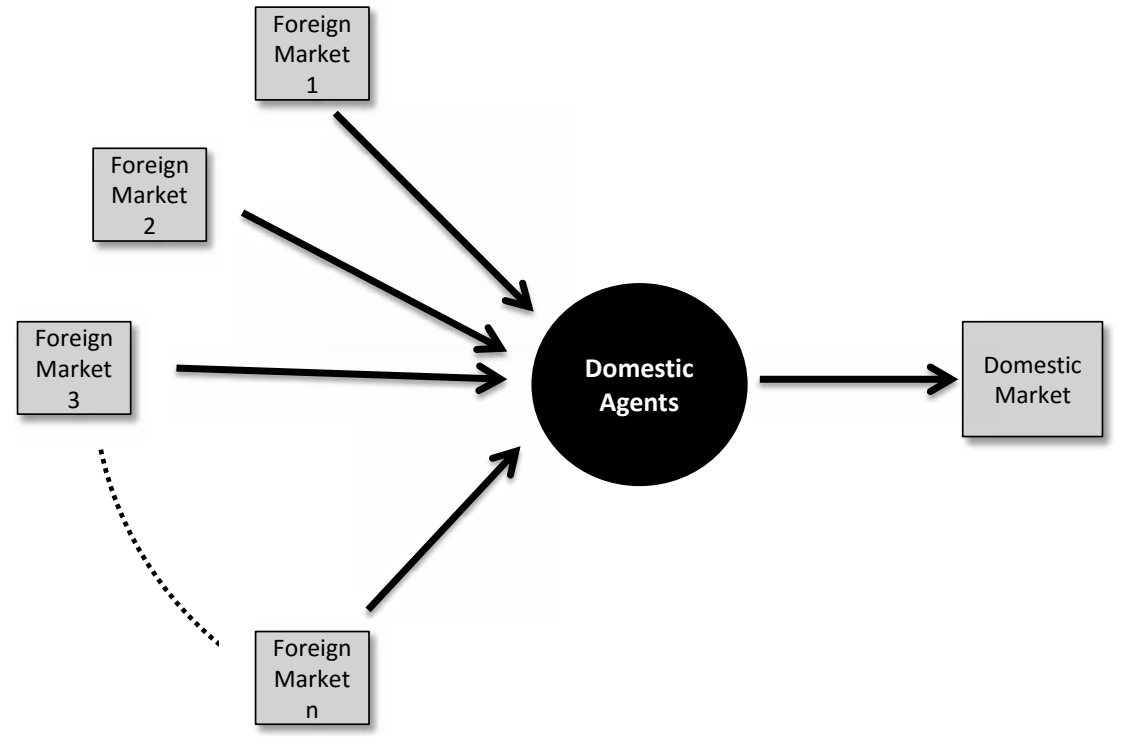

More precisely, let us recall that the unexpected volatility shock in a foreign country $f$ is denoted by $\varepsilon_{t, f}$ measured by the residual of regression (4) and that the attention paid by domestic investors in country $d$ to the market index of the foreign country $f$ is denoted by $G S I_{t, d \rightarrow f}$, both evaluated at period $t$. Then, the first stage of the empirical exercise is empirically quantified by estimating the regression (7). In this specification, as long as $\beta_{1}$ and $\beta_{2}$ are statistically different from zero, the attention paid by investors in country $d$ to volatility shocks arising in country $f$ is lagged with one and two days of delay, respectively.

$$
G S I_{t, d \rightarrow f}=\alpha+\beta_{\circ} \varepsilon_{t, f}+\beta_{1} \varepsilon_{t-1, f}+\beta_{2} \varepsilon_{t-2, f}+\mu_{t}
$$

Table 10 reports OLS estimations of equation 7 for each country in the sample (China is discarded since Google is banned in this location) considering the three most relevant trade partners as dictated by the bilateral trade intensity (see equation 6). To account for heteroskedasticity and autocorrelations in the error term, standard errors are computed following Newey and West (1987). The results indicates that the attention paid by investors from every country in the sample to the market volatility shocks of major trade partners tends to be positive and strongly statistically significant (only the coefficients of the third trade partner of Spain and France are negative and significant). More importantly, these effects are commonly observed with one or two days of delay which provides support to the theoretical argument of gradual diffusion of information.

The second stage of the empirical exercise attempts to disentangle the relationship between investors' domestic attention to both the domestic market and to the markets of major trade partners on the current volatility of the domestic market. Let us denote by $G S I_{t-i, d \rightarrow \bar{f}}$ the average Google Search Index of investors located in country $d$ toward the markets of the three most relevant trade partners. The relationships just commented are captured by the following expression:

$$
\sigma_{t, d}=\alpha+\sum_{i=0}^{2} \beta_{i} G S I_{t-i, d \rightarrow d}+\sum_{i=0}^{2} \gamma_{i} G S I_{t-i, d \rightarrow \bar{f}}+\mu_{t}
$$


First Major Trade Partner

Second Major Trade Partner

Third Major Trade Partner

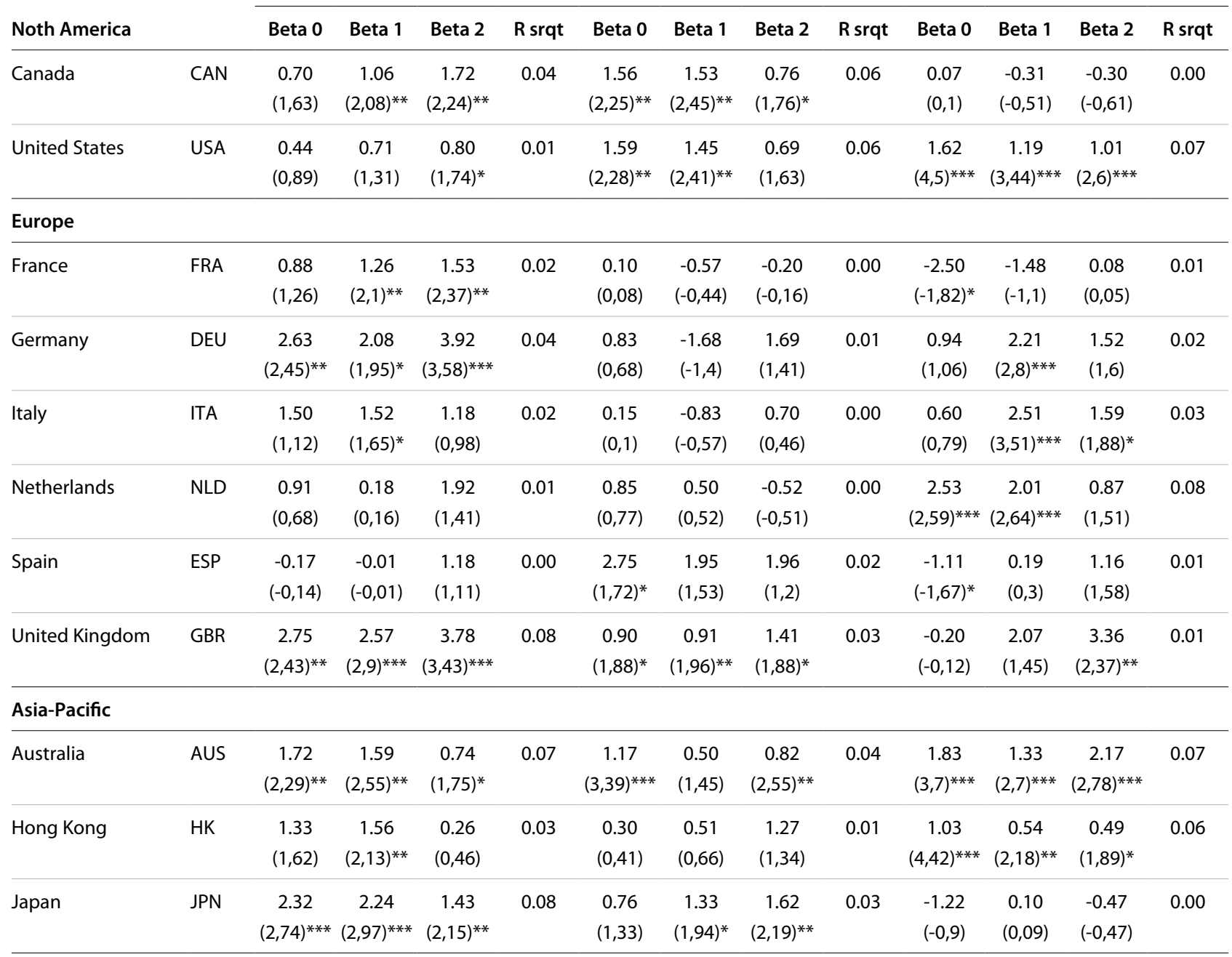

Estimation results of equation (7) for each country in the sample considering the three most relevant trade partners in the columns of the table. The relevance as trade partner is quantified by their trade intensity as given by equation (6). T-statistics and significance are corrected by heteroskedasticity and autocorrelated following Newey and west (1987). T-statistics are reported in parenthesis.

Significance is as follows: ${ }^{*}$ at $10 \%,{ }^{* *}$ at $5 \%$ and ${ }^{* * *}$ at $1 \%$.

Table 10 reports the OLS estimations of two different specifications of equation (8) depending on the inclusion of $G S I_{t-i, d \rightarrow \bar{f}}$ as explanatory variables. As before, standard errors and t-statistics are corrected by heteroskedasticity and autocorrelation following Newey and West (1987). The evidence indicates a clear pattern: domestic volatility is positively and significantly correlated with the attention paid by domestic investors to the domestic market. This observation holds for each country in the sample and across specifications. Moreover, these results indicate a contemporary effect given that most of the significant coefficients correspond in $\beta_{\circ}$. On the other hand, the evidence regarding the impacts of domestic attention to foreign markets upon domestic volatility is in line with the hypothesis of gradual diffusion. The coefficients $\gamma_{i}$ are positive and are statistically significant for 7 out of 11 countries in the sample and, as before, these impacts are mainly contemporaneous. 


\begin{tabular}{|c|c|c|c|c|c|c|c|c|}
\hline \multirow{2}{*}{ Noth America } & & \multicolumn{3}{|c|}{ Domestic Attention } & \multicolumn{4}{|c|}{ Foreign Attention } \\
\hline & & Beta 0 & Beta 1 & Beta 2 & Gamma 0 & Gamma 1 & Gamma 2 & R srqt \\
\hline \multirow[t]{4}{*}{ Canada } & CAN & 0,03 & 0,02 & 0,01 & & & & 0,30 \\
\hline & & $(5,07)^{* * *}$ & $(1,91)^{*}$ & $(2,17)^{* *}$ & & & & \\
\hline & & 0,03 & 0,02 & 0,01 & 0,03 & $-0,02$ & 0,01 & 0,32 \\
\hline & & $(3,39)^{* * *}$ & $(2,35)^{* *}$ & $(2,04)^{* *}$ & $(3,67)^{* * *}$ & $(-1,11)$ & $(0,71)$ & \\
\hline \multirow[t]{4}{*}{ United States } & USA & 0,08 & $-0,02$ & 0,00 & & & & 0,26 \\
\hline & & $(7,91)^{* * *}$ & $(-1,66)^{*}$ & $(0,5)$ & & & & \\
\hline & & 0,09 & $-0,02$ & $-0,01$ & $-0,01$ & 0,02 & 0,01 & 0,26 \\
\hline & & $(8,85)^{* * *}$ & $(-2,1)^{* *}$ & $(-0,9)$ & $(-0,88)$ & $(1,37)$ & $(0,97)$ & \\
\hline \multicolumn{9}{|l|}{ Europe } \\
\hline \multirow[t]{4}{*}{ France } & FRA & 0,09 & 0,01 & $-0,01$ & & & & 0,15 \\
\hline & & $(6,08)^{* * *}$ & $(0,58)$ & $(-0,72)$ & & & & \\
\hline & & 0,09 & 0,01 & $-0,01$ & 0,00 & $-0,00$ & 0,01 & 0,15 \\
\hline & & $(6,15)^{* * *}$ & $(0,62)$ & $(-0,9)$ & $(0,27)$ & $(-0,69)$ & $(1,15)$ & \\
\hline \multirow[t]{4}{*}{ Germany } & DEU & 0,04 & 0,00 & 0,00 & & & & 0,18 \\
\hline & & $(5,25)^{* * *}$ & $(0,53)$ & $(0,69)$ & & & & \\
\hline & & 0,03 & $-0,00$ & $-0,01$ & 0,02 & 0,01 & 0,01 & 0,21 \\
\hline & & $(3,5)^{* * *}$ & $(-0,21)$ & $(-0,91)$ & $(2,68)^{* * *}$ & $(1,74)^{*}$ & $(1,87)^{*}$ & \\
\hline \multirow[t]{4}{*}{ Italy } & ITA & 0,02 & 0,01 & $-0,00$ & & & & 0,07 \\
\hline & & $(3,22)^{* * *}$ & $(1,2)$ & $(-0,23)$ & & & & \\
\hline & & 0,01 & 0,00 & $-0,00$ & 0,02 & 0,01 & 0,00 & 0,11 \\
\hline & & $(1,91)^{*}$ & $(0,52)$ & $(-0,79)$ & $(3,5)^{* * *}$ & $(1,11)$ & $(0,75)$ & \\
\hline \multirow[t]{4}{*}{ Netherlands } & NLD & 0,03 & 0,00 & 0,01 & & & & 0,10 \\
\hline & & $(3,19)^{* * *}$ & $(0,21)$ & $(1,66)^{*}$ & & & & \\
\hline & & 0,02 & $-0,00$ & 0,01 & 0,02 & 0,00 & $-0,00$ & 0,12 \\
\hline & & $(2,39)^{* *}$ & $(-0,29)$ & $(1,39)$ & $(2,75)^{* * *}$ & $(0,5)$ & $(-0,17)$ & \\
\hline \multirow[t]{4}{*}{ Spain } & ESP & 0,03 & $-0,00$ & $-0,01$ & & & & 0,06 \\
\hline & & $(4,46)^{* * *}$ & $(-0,81)$ & $(-1,25)$ & & & & \\
\hline & & 0,03 & $-0,00$ & $-0,01$ & 0,01 & 0,00 & $-0,00$ & 0,06 \\
\hline & & $(4,14)^{* * *}$ & $(-0,78)$ & $(-1,17)$ & $(1,31)$ & $(0)$ & $(0)$ & \\
\hline \multirow[t]{4}{*}{ United Kingdom } & GBR & 0,05 & $-0,00$ & 0,01 & & & & 0,19 \\
\hline & & $(8,14)^{* * *}$ & $(-0,29)$ & $(1,49)$ & & & & \\
\hline & & 0,04 & $-0,00$ & 0,01 & 0,01 & $-0,00$ & 0,01 & 0,21 \\
\hline & & $(6,46)^{* * *}$ & $(-0,42)$ & $(0,72)$ & $(1,65)^{*}$ & $(-0,07)$ & $(1,65)^{*}$ & \\
\hline \multicolumn{9}{|l|}{ Asia-Pacific } \\
\hline \multirow[t]{4}{*}{ Australia } & AUS & 0,03 & 0,00 & 0,01 & & & & 0,17 \\
\hline & & $(5,61)^{* * *}$ & $(0,54)$ & $(1,61)$ & & & & \\
\hline & & 0,02 & $-0,00$ & 0,01 & 0,04 & $-0,00$ & 0,01 & 0,19 \\
\hline & & $(2,88)^{* * *}$ & $(-0,22)$ & $(1,17)$ & $(3,4)^{* * *}$ & $(-0,31)$ & $(0,81)$ & \\
\hline \multirow[t]{4}{*}{ Hong Kong } & HK & 0,03 & $-0,01$ & 0,01 & & & & 0,06 \\
\hline & & $(2,58)^{* * *}$ & $(-0,71)$ & $(0,84)$ & & & & \\
\hline & & 0,01 & $-0,01$ & 0,00 & 0,03 & 0,02 & 0,01 & 0,14 \\
\hline & & $(1,7)^{*}$ & $(-1,94)^{*}$ & $(0,13)$ & $(2,64)^{* * *}$ & $(2,66)^{* * *}$ & $(1,42)$ & \\
\hline \multirow[t]{4}{*}{ Japan } & JPN & 0,03 & 0,00 & $-0,00$ & & & & 0,11 \\
\hline & & $(5,17)^{* * *}$ & $(0,63)$ & $(-0,34)$ & & & & \\
\hline & & 0,03 & 0,00 & $-0,00$ & 0,00 & $-0,00$ & 0,01 & 0,11 \\
\hline & & $(4,92)^{* * *}$ & $(0,67)$ & $(-0,61)$ & $(0,46)$ & $(-0,44)$ & $(0,72)$ & \\
\hline
\end{tabular}

Estimation results of equation (8) for each country in the sample considering the three most relevant trade partners in the columns of the table. The relevance as trade partner is quantified by the trade intensity as given by equation (6).

T-statistics and significance are corrected by heteroskedasticity and autocorrelated following Newey and West (1987). T-statistics are reported in parenthesis. Significance is as follows: ${ }^{*}$ at $10 \%,{ }^{* *}$ at $5 \%$ and ${ }^{* * *}$ at $1 \%$. 
Overall, the results reported by table 9 point out that domestic attention reacts to foreign volatility surprises with delays which, in turn, is consistent with the slow diffusion hypothesis due to investors' limited attention. Additionally, table $10 \mathrm{com}-$ pletes the picture indicating that domestic markets contemporaneously react to investors' attention not only to the domestic market but also to the markets of major trade partners. Therefore, once information is captured and processed by local investors, the latter instantaneously react by incorporating the new data into the prices of domestic securities. 



\section{Conclusions and Future Research Lines}

The major concern of this study is to shed some light on the nature of volatility spillovers among major capital markets around the world by relying on network theory concepts. I introduce two networks, the International Volatility Network $(I V N)$ and the International Trade Network $(I T N)$, whose nodes stand for a set of large-cap stock markets. The links of the former structure capture significant volatility lead-lags between pairs of ETFs replicating MSCI market indices while the links from the latter encompass fundamental relationships across countries as measured by their bilateral trade flows.

Two features of the estimated adjacency matrix of the IVN are thoroughly scrutinized. On the one hand, the likelihood and intensity of the links in this structure are larger among pairs of countries from the same continent than pairs from different continents. In other words, the $I V N$ is organized in communities where countries from the same continent are tightly connected among themselves and weakly connected between continents. On the other hand, the observed volatility lead-lags are inconsistent with the traditional hypothesis of market efficiency. The comparison between the IVN and the ITN provides a plausible explanation for the community organization of the former. In particular, I show from different perspectives that the $I V N$ and the $I T N$ resemble each other closely, indicating that volatility tends to spread across fundamentally connected countries. Regarding the nature of volatility lead-lags, I argue that they can be explained by the gradual diffusion of information among investors subject to limited attention and home bias. I formally test this hypothesis by directly measuring the attention of domestic investors to foreign markets through the aggregate internet search data provided by Google. The data show that volatility surprises in major trade partners increase the attention of domestic investors, not contemporaneously, but with a delay. Nevertheless, once this information captures the attention of domestic investors, it is contemporaneously incorporated into the prices of domestic securities.

There are two promising future research lines related to this analysis. This study reports that Asian economies tend to shows a disproportionate influence as volatility spreaders compared to their role as trade partners. It seems interesting to see whether the centrality of countries is a stable feature or if it is strongly affected by developments such as Chinese Black Monday. Additionally, it has been shown that there are some markets acting as bellwether countries given their sizable impacts on most of the economies in the same continent. The "relative" investor attention paid to those countries might be a plausible explanation for this finding and it can be empirically tested following a similar approach to the current analysis. 



\section{References}

Alizadeh, S., T. Brandt, and F. X. Diebold, 2002, Range-Based Estimation of Stochastic Volatility Models, Journal of Finance 57, 1047-1092.

Andersen, T., T. Bollerslev, F. X. Diebold, and P. Labys, 2003, Modeling and forecasting realized volatility, Econometrica 71, 579-625.

Barigozzi, M., and C. Brownlees, 2016, Nets: Network Estimation for Time Series, SSRN - Working Paper, 1-43.

Bekaert, G., R. Hodrick, and X. Zhang, 2012, Aggregate Idiosyncratic Volatility, Journal of Financial and Quantitative Analysis 47, 1155-1185.

Billio, M., M. Getmansky, A. W. Lo, and L. Pelizzon, 2012, Econometric measures of connectedness and systemic risk in the finance and insurance sectors, Journal of Financial Economics 104, 535-559.

Bonacich, P., 1972, Factoring and weighting approaches to status scores and clique identification, The Journal of Mathematical Sociology 2, 113-120.

Bonacich, P., 1987, Power and Centrality: A Family of Measures, American Journal of Sociology 92, 1170-1182.

Bonacich, P., 2007, Some unique properties of eigenvector centrality, Social Networks 29, 555-564.

Cohen, L., and A. Frazzini, 2008, Economic links and predictable returns, Journal of Finance 63, 1977-2011.

Da, Z., J. Engelberg, and P. Gao, 2011, In Search of Attention, Journal of Finance 66, 1461-1499.

Diebold, F. X., and K. Yilmaz, 2009, Measuring Financial Asset Return and Volatility Spillovers, With Application to Global Equity Markets, The Economic Journal 119, $158-171$.

Diebold, F. X., and K. Yilmaz, 2012, Better to give than to receive: Predictive directional measurement of volatility spillovers, International Journal of Forecasting 28, 57-66.

Diebold, F. X., and K. Yilmaz, 2014, On the network topology of variance decompositions: Measuring the connectedness of financial firms, Journal of Econometrics 182, $119-134$. 
Diebold, F. X., and K. Yilmaz, 2015, Trans-Atlantic Volatility Connectedness Among Financial Institutions, .

Dimpfl, Thomas, and R.C. Jung, 2012, Financial market spillovers around the globe, Applied Financial Economics 22, 45-57.

Faruqee, H., S. Li, and I. Yan, 2004, The determinants of international portfolio holdings and home bias, IMF Working Papers.

French, K., and J. Poterba, 1991, Investor diversification and international equity markets, American Economic Review 81, 222-226.

Garman, M., and M. Klass, 1980, On the Estimation of Security Price Volatilities from Historical Data, The Journal of Business 53, 67-68.

Gastineau, G., 2010, The Exchange-Traded Funds Manual (John Wiley \& Sons, Inc., Hoboken, NJ, USA).

Hamao, Y., R. Masulis, and V. Ng, 1990, Correlations in Price Changes and Volatility across International Stock Markets, Review of Financial Studies 3, 281-307.

Hameed, A., R. Morck, J. Shen, and B. Yeung, 2015, Information, Analysts, and Stock Return Comovement, Review of Financial Studies 28, 3153-3187.

Hautsch, N., J. Schaumburg, and M. Schienle, 2015, Financial Network Systemic Risk Contributions, Review of Finance 9, 685-738.

Hong, H., and J. C. Stein, 2007, Disagreement and the Stock Market, Journal of Economic Perspectives 21, 109-128.

Hou, Kewei, 2007, Information Diffusion and the Industry Lead-lag Effect in Stock Returns, Review of Financial Studies 20, 1113-1138.

Huberman, G., and T. Regev, 2001, Contagious Speculation and a Cure for Cancer: A Nonevent that Made Stock Prices Soar, The Journal of Finance 56, 387-396.

Hughen, J., and P. Mathew, 2009, The efficiency of international information flow: Evidence from the ETF and CEF prices, International Review of Financial Analysis $18,40-49$.

Investment Company Institute, ed., 2015, Investment Company Fact Book (Investment Company Institute).

Jackson, M. O., 2010, Social and Economic Networks (Princeton University Press).

Jung, R.C., and R. Maderitsch, 2014, Structural breaks in volatility spillovers between international financial markets: Contagion or mere interdependence?, Journal of Banking \& Finance 47, 331-342.

Khorana, A., E. Nelling, and J. Tester, 1998, The emergence of country index funds, Journal of Portfolio Management 24, 78-84. 
King, M., and S. Wadhwani, 1990, Transmission of Volatility between Stock Markets, Review of Financial Studies 3, 5-33.

Lin, W., R. Engle, and T. Ito, 1994, Do Bulls and Bears Move Across Borders ? International Transmission of Stock Returns and Volatility, Review of Financial Studies 7, 507-538.

Menzly, Lior, and Oguzhan Ozbas, 2010, Market segmentation and cross-predictability of returns, Journal of Finance 65, 1555-1580.

Newey, W., and K. West, 1987, A simple, positive semi-definite, heteroskedasticity and autocorrelation consistent covariance matrix, Econometrica 55, 703-708.

Newman, M. E. J., 2003, Mixing patterns in networks, Physical Review E 67, 026126.

Newman, M. E. J., 2004, Analysis of weighted networks, Physical Review E.

Newman, M. E. J., 2010, Networks: An Introduction Oxford University Press (Oxford University Press).

Peralta, G., 2015, Network-based measures as leading indicators of market instability: the case of the Spanish stock market, Journal of Network Theory in Finance 1, 91-122.

Rizova, Savina, 2010, Predictable Trade Flows and Returns of Trade-Linked Countries, AFA 2011 Denver Meetings Paper.

Strohsal, T., and E. Weber, 2012, The Signal of Volatility. Discussion Paper.

Tibshirani, R., 1996, Regression Shrinkage and Selection via Lasso, Journal of the Royal Statistical Society: Series B (Statistical Methodology) 58, 267-288.

Tse, Chi K., J. Liu, and F. C. M. Lau, 2010, A network perspective of the stock market, Journal of Empirical Finance 17, 659-667.

Tse, Y., and V. Martinez, 2007, Price discovery and informational efficiency of international iShares funds, Global Finance Journal 18, 1-15.

Van Nieuwerburgh, S., and L. Veldkamp, 2009, Information immobility and the home bias puzzle, Journal of Finance 64, 1187-1215.

Zou, H., 2006, The Adaptive Lasso and Its Oracle Properties, Journal of the American Statistical Association 101, 1418-1429. 



\section{Acknowledgements}

I would like to thank Ramiro Lozada and the participants in the internal seminars at both, CNMV and Universidad Carlos III de Madrid for helpful comments. The opinions in this paper are the sole responsibility of the author and they do not necessarily coincide with those of the CNMV. Gustavo Peralta acknowledges financial support from the CNMV. 



\section{Appendix A. Estimation of the IVN}

\section{A.1 General Procedure for estimating the IVN}

This appendix details the procedure to estimate matrix $B$ in (1) after filtering the volatilities series by implementing equation (3). The optimization procedure is described by equation (5) and it is specifically performed as follows:

1) Obtain the OLS estimation coefficients $\hat{\beta}_{\text {ols,i }}$ by regressing $\hat{\varepsilon}_{t, i}$ on $\hat{\varepsilon}_{t-1}$

2) Estimate $\hat{\beta}_{\text {alasso, } i}$ on a row-by-row basis by optimizing $(5)$ while selecting $(\mu, v)$ by means of 3 -fold cross validation where $\hat{\eta}_{i, j}=\left(\left|\hat{\beta}_{\text {ols }, i j}\right|\right)^{-v}$

\section{A.2 Estimation of Adaptive Lasso coefficients $\hat{\beta}_{i, \text { alasso }}$ of $y$ on $X$}

1) Compute $X^{*}=X / \hat{\eta}$

2) $\hat{\beta}_{\text {alasso }}^{*}=\arg \min _{\beta}\left(\left\|y-X^{*} \beta\right\|_{2}^{2}+\mu\|\beta\|_{1}\right)$

3) The corrected Adaptive Lasso coefficients are given by $\hat{\beta}_{\text {alasso }}=\hat{\beta}_{\text {alasso }}^{*} / \hat{\eta}$ 



\section{Appendix B. Trading Hours by Countries}

Trading hours by countries sorted by UTC opening

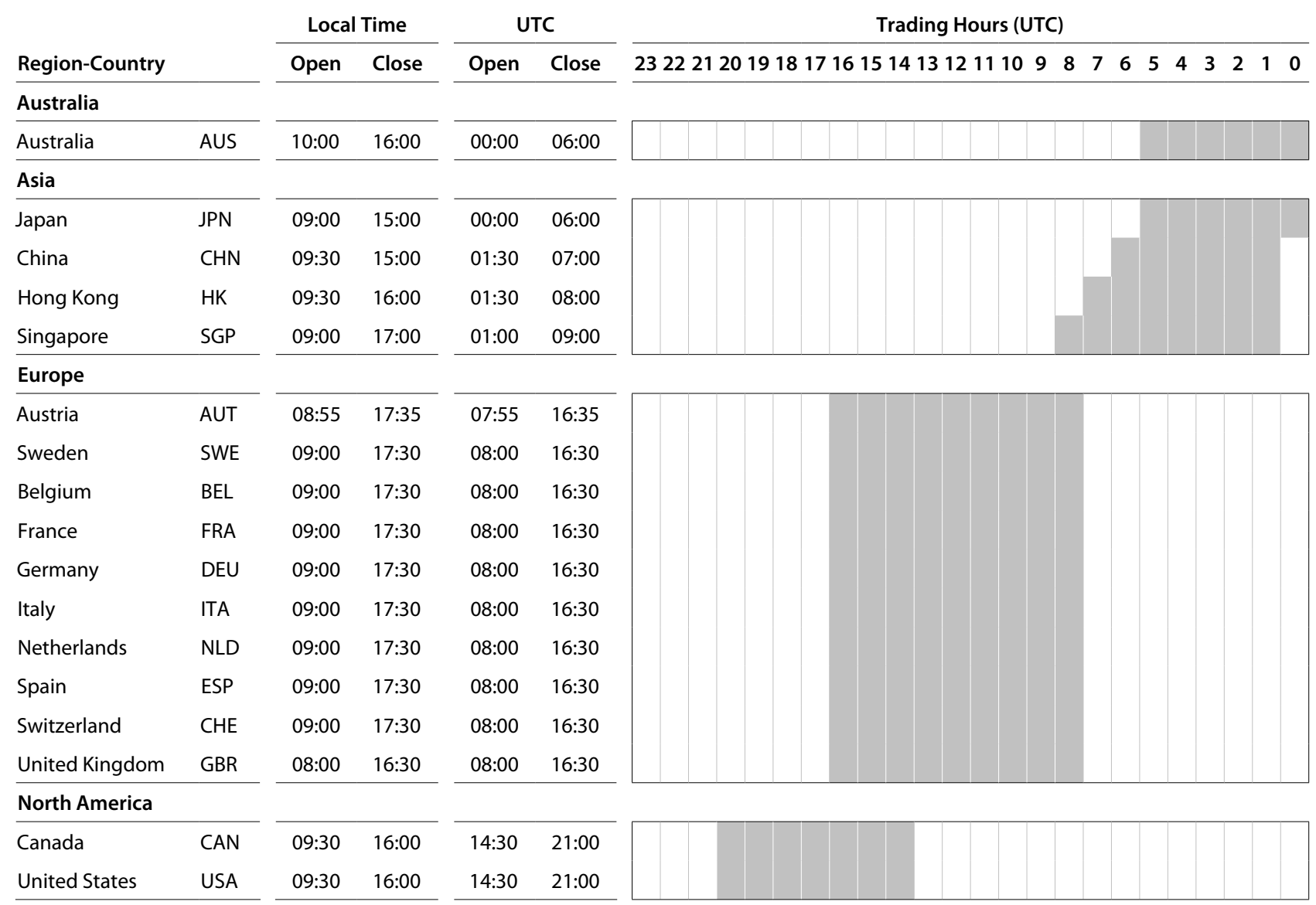





\section{Appendix C. Descriptive Statistics for the log Volatility}

Descriptive statistics log Volatility for the period 2013-6 to 2015-12

\begin{tabular}{|c|c|c|c|c|c|c|c|c|c|c|c|}
\hline \multirow[b]{2}{*}{ Countries } & \multirow[b]{2}{*}{ Mean } & \multirow[b]{2}{*}{ Median } & \multirow[b]{2}{*}{ Min } & \multirow[b]{2}{*}{$\operatorname{Max}$} & \multirow[b]{2}{*}{ Std } & \multirow[b]{2}{*}{ Skewness } & \multirow[b]{2}{*}{ Kurtosis } & \multicolumn{4}{|c|}{ Autocorrelation } \\
\hline & & & & & & & & Lag 1 & Lag 5 & Lag 10 & Lag 20 \\
\hline \multicolumn{12}{|l|}{ North America } \\
\hline Canada & -10.23 & -10.24 & -13.43 & -6.14 & 0.92 & 0.23 & 0.49 & 0.46 & 0.40 & 0.28 & 0.26 \\
\hline United States & -10.63 & -10.64 & -13.30 & -5.77 & 0.99 & 0.34 & 0.78 & 0.49 & 0.27 & 0.13 & 0.09 \\
\hline \multicolumn{12}{|l|}{ Europe } \\
\hline Austria & -10.61 & -10.65 & -13.51 & -6.95 & 0.89 & 0.25 & 0.81 & 0.26 & 0.14 & 0.17 & 0.06 \\
\hline Belgium & -10.79 & -10.78 & -13.95 & -7.06 & 0.88 & 0.20 & 0.65 & 0.28 & 0.23 & 0.13 & 0.11 \\
\hline France & -10.48 & -10.49 & -13.18 & -6.75 & 0.94 & 0.18 & 0.42 & 0.34 & 0.28 & 0.12 & 0.16 \\
\hline Germany & -10.42 & -10.40 & -12.60 & -6.74 & 0.93 & 0.18 & -0.02 & 0.42 & 0.30 & 0.17 & 0.22 \\
\hline Italy & -9.94 & -9.96 & -12.15 & -7.05 & 0.80 & 0.44 & 0.45 & 0.32 & 0.23 & 0.12 & 0.12 \\
\hline Netherlands & -10.82 & -10.81 & -13.58 & -6.42 & 0.96 & 0.10 & 0.57 & 0.39 & 0.31 & 0.16 & 0.20 \\
\hline Spain & -10.14 & -10.12 & -12.66 & -6.92 & 0.89 & 0.24 & 0.29 & 0.32 & 0.21 & 0.08 & 0.12 \\
\hline Sweden & -10.45 & -10.47 & -12.80 & -6.95 & 0.84 & 0.33 & 0.65 & 0.33 & 0.23 & 0.12 & 0.14 \\
\hline Switzerland & -10.91 & -10.95 & -13.59 & -6.91 & 0.88 & 0.35 & 0.93 & 0.36 & 0.22 & 0.16 & 0.18 \\
\hline United Kingdom & -10.67 & -10.67 & -13.51 & -7.12 & 0.85 & 0.28 & 0.87 & 0.43 & 0.29 & 0.17 & 0.16 \\
\hline \multicolumn{12}{|l|}{ Asia-Pacific } \\
\hline Australia & -10.58 & -10.59 & -14.40 & -7.06 & 0.92 & 0.01 & 0.80 & 0.40 & 0.33 & 0.26 & 0.23 \\
\hline China & -10.26 & -10.29 & -12.95 & -5.58 & 0.92 & 0.31 & 1.15 & 0.45 & 0.29 & 0.18 & 0.17 \\
\hline Hong Kong & -10.80 & -10.84 & -13.23 & -5.94 & 0.87 & 0.51 & 1.46 & 0.42 & 0.23 & 0.15 & 0.10 \\
\hline Japan & -10.81 & -10.80 & -13.04 & -6.97 & 0.89 & 0.19 & 0.08 & 0.45 & 0.27 & 0.14 & 0.15 \\
\hline Singapore & -11.05 & -11.03 & -13.92 & -6.78 & 0.90 & 0.35 & 1.30 & 0.35 & 0.26 & 0.17 & 0.18 \\
\hline \multicolumn{12}{|l|}{ Global } \\
\hline First PC & -43.29 & -43.46 & -50.04 & -27.54 & 2.95 & 0.72 & 1.51 & 0.47 & 0.32 & 0.17 & 0.19 \\
\hline
\end{tabular}




